\title{
EXCAVACIONESY ESTUDIOS ETNOHISTÓRICOS DEL MONUMENTO ARQUEOLÓGICO SAN BORJA NORTE, VALLE DE LIMA
}

\author{
Alberto Bueno Mendoza \\ UnIVERSIDAD NACIONAL MAYOR DE SAN MARCOS \\ abuenom@unmsm.edu.pe
}

\section{RESUMEN}

El Monumento Arqueológico San Borja Norte es magnífico testimonio arquitectónico del Centro Urbano Pre-Tawantinsuyu Limatambo, cuya área construida originada antes de la invasión española se emplazaba entre la actual avenida Canadá y el antiguo aeropuerto de Limatambo.

El Monumento Arqueológico de San Borja Norte está construido en adobón (barro apisonado), con muros a base de bloques imbricados por adosamientos consecutivos solucionados en suave talud al exterior; su elevación fue lograda mediante la técnica de rellenar compartimientos internos traslapados en verticalidad, teniendo muros medianeros interiores que buzan de norte a sur y de este a oeste, sirviendo de contención a tales rellenos. Esta arquitectura externa se superpone a la más antigua del horizonte medio en planta y elevación rectilineal es. La más visible al exterior es masiva y técnicamente repetitiva en el monumento. Sus perfiles externos sur, este y oeste, así como un remetido frente norte muy destruido, muestran características típicas descritas. Entre cuatro a seis muros externos adosados consecutivamente en suave talud, encierran, cercan y delimitan a la unidad arquitectónica interna conservada de siete metros de altura en el ángulo sur-oeste. Los muros con bloques imbricados son morfología arquitectónica intermedio tardía y se correlaciona con arquitecturas arqueológicas de similar tipificación en otras markas paralelas asentadas en distintos rumbos del Valle de Lima, compartiendo técnicas constructivas similares.

El Monumento de San Borja Norte, como arquitectura local perteneciente a la marka Lima entra a formar parte del Tawantinsuyu, sufriendo la gente los trastornos propios del dominio cusqueño. Se impone la institución política y administrativa denominada "Tambo" para funcionar como organismo de control social y político en el orden local. Este monumento arqueológico es el mejor conservado en el distrito de San Borja, terreno del antiguo centro poblado arqueológico Limatambo pre-español.

Palabras clave: San Borja Norte, monumento arqueológico, pre-español, datos arqueológicos, datos etnoshistóricos. 


\section{Abstract}

The San Borja Norte Archaeological Monument is a magnificent architectural testimony of the Pre-Tawantinsuyu Limatambo Urban Center, whose built area originated before the Spanish invasion was located between the current Canada Avenue and the former Limatambo airport.

The Archaeological Monument of San Borja Norte is built in adobon (rammed clay), with walls based on blocks imbricated by consecutive fixings solved in soft slope to the outside; Its elevation was achieved through the technique of filling internal compartments overlapped vertically, having interior medianero walls that buzz from north to south and east to west, serving as a restraint to such fillings. This external architecture is superimposed on the oldest of the average horizon in plant and rectilineal elevation is. The most visible to the outside is massive and technically repetitive in the monument. Its south, east and west external profiles, as well as a remittance of the heavily destroyed north face, show typical characteristics described. Between four and six outer walls consecutively on a smooth slope, they enclose, enclose and delimit the preserved internal architectural unit of seven meters high in the south-west angle. The walls with interlocking blocks are late interim architectural morphology and correlate with archaeological architectures of similar typification in other parallel markas settled in different courses of the Valley of Lima, sharing similar constructive techniques.

The Monument of San Borja Norte, as a local architecture belonging to the Lima marka comes to form part of Tawantinsuyu, suffering people the disorders typical of Cusco. It imposes the political and administrative institution called "Tambo" to function as a body of social and political control in the local order. This archaeological monument is the best preserved in the district of San Borja, land of the old archeological center pre-Spanish Limatambo.

KeYwords: San Borja Norte, archaeological monument, pre-Spanish, archaeological data, etnoshistorical data.

\section{INTRODUCCIÓN GENERAL}

Entre los años 1970-1975 se incrementó la urbanización de los ex - terrenos de cultivo ubicados en San Borja Norte y Suroeste del Distrito de San Luis. El gobierno militar liderado por el General Juan Velasco Alvarado ejecuta en el área una serie de edificaciones estatales (La Videna, El Cuartel General del Ejército, Ministerio de Pesquería, un gran local de la Marina, etc.), reserva enormes terrenos para proyectos constructivos a futuro (grandes terrenos para la Compañía Peruana de Teléfonos), así como compañías inmobiliarias privadas promueven urbanizar los terrenos aledaños para residencias particulares. El resultado fue un panorama de edificios estatales, locales de empresas privadas comerciales, urbanizaciones promovidas por el estado, montículos arqueológicos -unos más grandes que otros- y una zona con ocupantes precarios inmediatamente al norte del ex - Ministerio de Pesquería (el asentamiento humano San Juan Masías).

Durante el segundo gobierno del Arquitecto Fernando Belaúnde Terry (1980-1985) ENACE ejecuta el proyecto arquitectónico "Conjunto Torres de San Borja". Terminadas estas obras nosotros éramos testigos cómo las compañías constructoras contratistas -por ahorro- amontonan los escombros en el terreno alrededor del montículo arqueológico, ubicado contiguo a los edificios de vivienda, Avenida Canadá y esquina con la Avenida Arqueología.

Después de la inauguración del Conjunto Habitacional, los escombros de construcción amontonados casi cubrían al monumento por tres de sus lados. También notamos que dos ocupantes precarios 
vivían al pie de tales escombros hacia el frente sur; por los años 1984-1985 éstos aumentaron, pues dos nuevos aparecieron con chozas de esteras sobre los escombros de construcción. Si no se hubiera intervenido, el área habría continuado siendo invadida. En este punto debemos otorgar gran mérito a la Municipalidad de San Borja, pues en 1986 se retiró a los ocupantes precarios y fueron erradicadas toneladas de escombros de construcción para dejar libre al monumento.

Nosotros que siempre estamos interesados en lo que pudiera ocurrirle al monumento, nos complacimos de la acción municipal a favor de su limpieza y preservación, decidiendo presentarnos al Concejo Distrital, cuando su local se encontraba en la Avenida San Borja Sur.

Mientras tanto, por su cuenta, la Municipalidad había oficiado al INC para que se encargue de los trabajos arqueológicos con miras a construir en el área un Centro Cultural. El INC presentó un presupuesto millonario para aquellos años, lo cual desanimó momentáneamente a las autoridades municipales.

En el INC nos enteramos de la situación, de tal manera que decidimos plantear una alternativa congruente: el convenio bilateral. Para ello conversamos en la Universidad de Lima, obteniéndose la aceptación de las autoridades de Humanidades, quienes autorizaron al Arqueólogo Alberto Bueno Mendoza a realizar las coordinaciones con el municipio. Es así que el Alcalde Dr. Hugo Sánchez Solari acepta el Convenio para ejecución del Proyecto y acciones pertinentes.

El Convenio se firmó en la Municipalidad de San Borja entre el Dr. Hugo Sánchez Solari y la Rectora Dra. Ilse Wisotzky el 10 de diciembre de 1987, despertando magníficas expectativas para el monumento.

Desde fines de 1986 habíamos redactado el proyecto y veníamos gestionando en el INC un permiso para los trabajos, cuya autorización recién fue publicada en "El Peruano" el 17 de diciembre de 1987 (Resolución Suprema N³46-87-ED). Esta Resolución autoriza al arqueólogo Alberto Bueno Mendoza (AB-80-01) y a los convenientes para ejecutar el Proyecto tramitado.

Entre los meses de marzo-abril (1988) realizamos coordinaciones y acciones para los trabajos preparatorios en el Monumento Arqueológico, tanto en las Oficinas de la Municipalidad de San Borja como en el campo:

1. Presentación de documentos para tramitar la adquisición de equipo, herramientas, instrumentos y artículos para trabajo de campo. La Municipalidad adquirió las provisiones según lista presentada.

2. Trámites en la Municipalidad para construcción del campamento, el que consta de los siguientes ambientes: caseta de vigilancia y guardianía, galpón para herramientas y depósito de materiales, gabinete de estudios y administración. En el mes de Julio de 1988 se terminó de construir la caseta, según plano coordinado con la Alcaldía y tramitado en la sección Abastecimientos del Concejo.

3. Los problemas económicos nacionales atrasaron e hicieron lentos los trámites para ultimar los preparativos y convocar al personal para los trabajos, dificultades superadas en el mes de agosto (1988).

4. Durante los meses de julio y agosto, la Universidad de Lima financió el trabajo de Topografía realizado por el especialista de la Universidad Agraria (CIZA) señor Bernardino Ojeda, conjuntamente con nuestra asistencia, coordinación y supervisión. 
5. El plano topográfico permite acotar en área la excavación arqueológica, pasar a la cuadriculación respectiva y plantear la estrategia de roturación del suelo.

6. El arqueólogo Anselmo Lozano Calderón ingresa a trabajar en agosto como Jefe de Campo; con su concurso hemos procedido a metrar el área por sectores y cuadrículas en aplicación de la planificación de las excavaciones.

7. La convocatoria para el personal de obreros se cumplió entre fines de Agosto y comienzos de Septiembre, los cuales realizan trabajos de limpieza y escombramiento de superficie. Restos de escombros de construcción, basura, deyecciones humanas acumuladas sobre el monumento y trastos de covachas ocupadas por vagos, amontonan unas cinco toneladas de desperdicios para erradicar.

Desde un comienzo hemos trabajado con cinco obreros; los primeros nombres son los siguientes:
a. Daniel Pérez Mendoza
L.E. $\mathrm{N}^{\circ} 07590638$
b. (vigilante nocturno).
c. Moisés Rodríguez Mallma
L.E. $N^{\circ} 21252292$
d. David Samuel Bartolo Quispe
L.E. $\mathrm{N}^{\circ} 21252949$
e. Manuel Caycho Aragón
L.E. $\mathrm{N}^{\circ} 07693916$.
f. Luis Caycho Aragón
L.E. $\mathrm{N}^{\circ} 07693915$.

Desde entonces ingresaron y salieron numerosos obreros debido a la desventaja del salario mínimo que les abonaba el municipio.

La Municipalidad de San Borja en Convenio con la Universidad de Lima ejecutan el Proyecto de Investigaciones Arqueológicas y al presente ambas instituciones cumplieron a cabalidad los puntos de tal convenio. El Boletín Municipal de San Borja números 31-32 (febrero de 1988), publicó en su página 14 dedicada a Bienes Culturales, un artículo titulado "Investigan Huacas", donde se da cuenta de los detalles del Proyecto.

Como el sitio carece de bibliografía o datos escritos, la Dirección del Proyecto inicia una pesquisa sobre fuentes etnohistóricas y otros documentos que informaran acerca del sitio. Esta tarea fue continua pues el monumento ha estado ocupado hasta 1988 (igual que el AA.HH. San Juan Masías urbanizado posteriormente), sin embargo, sus datos siguen siendo escasos.

Por la investigación aerofotográfica es de particular importancia precisar que existen vuelos de los años 1944, 1946 y 1952, donde conocemos que el monumento en estudio no se encontraba solo, sino que formaba parte de -al menos- cuatro montículos: se conservan dos fragmentos arquitectónicos en el ángulo noreste del Parque Túpac Amaru y otro pequeño montículo en la esquina sureste, al interior del Instituto Peruano del Deporte (al costado de la avenida Canadá, San Luis). Hay datos orales respecto a que cuando se niveló el terreno de "Las Torres", apareció material arqueológico.

En atención a la calidad de la arquitectura monumental descubierta, el cumplimiento de los objetivos propuestos y los efectos multiplicadores exitosos para ambas instituciones firmantes del Convenio de Cooperación Cultural, la Municipalidad de San Borja y la Universidad de Lima coincidieron en firmar un segundo Convenio para prorrogar su cooperación por los años 1990-1991. Considerándose que los descubrimientos de la Arquitectura Arqueológica necesitan continuidad de los trabajos hasta su culminación, las instituciones decidieron otorgar su conformidad para prorrogar por dos nuevos 
años (1992-1993), en forma definitiva, la etapa final de los trabajos.

Las excavaciones arqueológicas continuaron durante estos años, después el INC ejecutó el proyecto de Conservación y Restauración del Monumento, como etapa final de los trabajos en el sitio. El cronograma de trabajo fue cursado a las instituciones convenientes siendo aprobado en todas sus partes.

\section{Los TRABajos InICIALES}

En un sitio arqueológico los trabajos empiezan desde que se hacen los primeros contactos, trámites, coordinaciones, organización, etc. para continuarse con las propias labores de campo: prospección, descripción, croquis, acopio de fotos aéreas, identificación tipológica de la clase de sitio, documentación fotográfica previa a los trabajos y otros datos del entorno; incluso, tratar de elaborar una historia de las vicisitudes del monumento hasta donde sea posible, por el método de aproximaciones sucesivas y/o documental.

Estas tareas han sido cumplidas en San Borja, cuyos resultados están utilizándose en los informes, ya que recordaremos que nuestro sitio en estudio carecía de datos arqueológicos.

Las labores técnicas arqueológicas suceden a continuación. Los levantamientos topográficos se ejecutan usando teodolito para obtener el primer plano de planta de toda el área, así como para calcular el metraje $\left(7,696 \mathrm{~m}^{2}\right)$ y pasar al relevamiento de otro plano con curvas de nivel, muy útil para acotación topográfica del terreno. Acotado el terreno, pasamos al señalizado con tiza blanca, haciendo visible de esta manera el sistema de cuadrículas trazadas ( 11 x $11 \mathrm{~m}$. c/u). Utilizando brújula y la Carta Nacional establecemos el norte geográfico, así como los demás rumbos, lo cual permite dividir el conjunto acotado en cuatro frentes: norte, sur, este y oeste. El objetivo es sistematizar el registro, acopio de datos y operaciones precedentes; siempre utilizando brújula que oriente al norte, pasamos a precisar y señalar el punto cero (Datum), el cual se constituye en el eje de todo el sistema de acotación, planimetría del proceso de excavaciones, gráficos de todo tipo, ubicación topográfica de hallazgos importantes, de los descubrimientos arquitectónicos sectorizados, así como la identificación del rumbo de los muros aflorantes en las cuadrículas de excavación.

Acto seguido ejecutamos la segunda operación en las cuadrículas: acotamos ahora los bordos de separación entre cada cuadrícula de excavación; esta nueva acotación -siempre usando estacas plantadas en forma fija- es para colocar pitas que indican la reservación de un metro a cada lado del cuadro de excavación, resultando al final bordos adyacentes de dos metros en ejes de simetría reticular.

Las labores reseñadas apuntan a aclarar que nuestra teoría metodológica proviene de la aplicación geométrica a la topografía arqueológica del racionalismo matemático de Descartes.

Llamamos la atención sobre este planteamiento teórico metodológico porque es consustancial al trabajo arqueológico de campo. La particularidad de la geometría cartesiana es que examina los problemas de las relaciones topológicas de la geometría plana, es decir, que el número de dimensiones no sobrepasa de dos: longitud (norte-sur) y ancho (este-oeste). Empero, incluso, intuye la tridimensionalidad, según F. Van Schooter (su comentarista y traductor al latín).

Descartes fue un convencido que basta examinar cualquier problema topográfico en dos dimensiones y extenderlo con apoyo del método analítico a una tercera dimensión (volumetría), empleando proyecciones ortogonales sobre dos planos topológicamente perpendiculares (estudio de las reglas cartesianas), permitiendo la preparación de la tarea para comprenderla y tener noción de la denominada magnitud. 
Según regla cartesiana pertinente "una vez abstraídos los términos de una dificultad, nos ocuparemos únicamente de las magnitudes en general” (Descartes, 1910, p. 40 y 55).

"No podemos servirnos aquí de la inteligencia pura exclusivamente, sino de la inteligencia apoyada por las figuras imprecisas de la imaginación porque lo que se dice de las magnitudes en general es posible referirlo a una magnitud en particular" (Descartes, 1971, p. 348 y ss.).

“...esta parte de nuestro método no ha sido inventado para resolver problemas matemáticos, sino que el conocimiento de las matemáticas es necesario únicamente para ejercitarse en la práctica de este método" (id. p. 39).

"Como el razonamiento es en palabras, importa mucho distinguir cuidadosamente aquella idea de que nuestra inteligencia debe estar representada en cada palabra (id., p. 349); ante todo se debe establecer la claridad en lo que respecta a la extensión, que debe distinguirse de lo extenso, a pesar que la extensión debe ser comprendida por lo que tiene de extenso".

Así entonces, el concepto de "lugar" es planteado por las relaciones generadas a partir de los conceptos extenso-extensión (magnitudes topológicas). Según la regla explicada Descartes compara entre sí:

"Tres maneras de hablar: la extensión ocupa lugar, el cuerpo tiene extensión y la extensión no es un cuerpo" (id., p. 349).

A diferencia de la extensión, lo extenso se define del siguiente modo:

"Por extensión entendemos todo lo que tiene longitud, ancho y profundidad, sin investigar ahora si se trata de un cuerpo verdadero o solamente de un espacio" (id., p. 349).

Ahora ya es posible excluir definitivamente la figura del número de las causas primeras:

"Si se trata de una figura, suponemos un sujeto extenso; si de un cuerpo, pensamos que se trata de un sujeto idéntico, porque posee longitud, ancho y profundidad; si se trata de una superficie, la consideramos larga y ancha omitiendo la profundidad sin negarla" (id., p. 351).

De esta manera la fisonomía de la matemática universal cartesiana se define plenamente: es geometría universal y general. Declara:

"Nos ocupamos de un objeto extenso, no considerando en él más que esta extensión y prescindiendo deliberadamente de la palabra "cantidad"... Suponemos que todas las cuestiones han sido llevadas a un punto en que el único objeto consiste en buscar cierta extensión comparándola con otra ya conocida... para conseguir este fin nos basta considerar en la extensión los elementos que puedan apoyarnos a exponer las diferencias de las proporciones. Estos elementos se presentan en número de tres: dimensión, unidad y figura (id., p. 352). Por "dimensión" se entiende tanto al proceso de medición como el modo y la razón según los cuales una forma es considerada como mensurable”.

"La medida que es el número, constituye hablando con propiedad, un tipo de medición; si consideramos las partes en orden relativamente al todo, decimos que contamos; si, al contrario, consideramos el todo dividido en partes, igualmente lo medimos. El peso de las formas, la velocidad del movimiento, la división del siglo en años y días, es algo real; no así la división del día en horas y minutos, etc. Sin embargo, todas esas divisiones son idénticas, si las consideramos sólo desde el punto de vista de la dimensión como lo hacemos aquí al igual que en las disciplinas matemáticas".

De este modo se define de una manera terminante la transferencia del problema físico al problema matemático y viceversa. "Las tres dimensiones del cuerpo: longitud, ancho y profundidad, no difieren 
más que en el nombre; nada impide tomar en un sólido cualquier extensión como longitud, otra extensión como ancho, etc.". (id, p. 352).

Después de la definición de "lugar" es éste el segundo paso destinado a preparar la introducción del sistema de coordenadas.

A partir de la comprensión de la dimensión, en el conjunto de todas las dimensiones posibles, necesariamente debe introducirse algo que constituya el fundamento general ("propiedad universal", según Descartes), estableciente de la correlación entre tales constantes. Este fundamento es la unidad de medición enunciado por Descartes:

"La unidad, es aquella naturaleza en que deben participar todas las cosas que se comparan entre sí. Cuando en una cuestión no haya alguna unidad determinada, podemos tomar como tal una de las magnitudes dadas o cualquier otra magnitud y ella será la medida común a todas las demás; consideramos que tiene tantas dimensiones como hay en los términos extremos que se comparan; esto se concibe simplemente como algo extenso, haciendo abstracción de otra determinación, viniendo a ser lo mismo que el punto de los geómetras, cuando por su movimiento componen la línea, el cuadrado, etc.".

La cita precedente explica cómo para Descartes la matemática deviene métrica. Así mismo llama la atención el orden en que se examina el punto, la línea y la superficie, para derivar hacia las figuras, formadas por ideas configurantes de todas las cosas.

"De las mil diversas clases de figuras, emplearemos sólo las que expresen más fácilmente todas las diferencias de relaciones y proporciones. Dos clases de cosas se comparan entre sí: cantidades y magnitudes; para presentarlas a nuestra inteligencia tenemos dos clases de figuras: los puntos que designan un "número triangular", son figuras destinadas a representar cantidades; en tanto que las figuras continuas e indivisibles como un triángulo, un cuadrado, etc., son magnitudes (id., p. 353). Todas las relaciones entre las figuras, y en general, entre los seres de la misma especie se reducen a dos principales: el orden y la medida. El orden de las magnitudes se establece así, directamente, mediante el examen consecutivo y por pares de éstas, mientras que la medida la establecemos de manera indirecta, con apoyo de la unidad".

Valiéndose de la unidad, Descartes sienta una correspondencia cruzada entre los conceptos de cantidad y orden, por un lado, y los de medida y magnitud por otro.

La complejidad de la correlación establecida entre la magnitud y la medida, así como el hecho táctico que el orden constituye en todas las relaciones (el necesario eslabón intermedio), se explica por la circunstancia que todas las relaciones se plantean todavía, única y exclusivamente, con apoyo del método y operando dentro de éstas, tales observaciones son el corolario del examen precedente con las que Descartes culmina esa especie de "preparación ideológica" para introducir las coordenadas y fundar la geometría analítica. Concluimos, entonces, que es preciso abstraer las proporciones tanto de las figuras sobre las que se ocupan los geómetras como de cualquier materia que tratemos; para tales operaciones basta plasmar las superficies rectilíneas y rectangulares o las líneas rectas que también son figuras, porque nos sirven tanto como las superficies para representar un proceso realmente extenso, representando -todas- las magnitudes continuas, lo mismo que la cantidad o el número. Los rectángulos y los segmentos de las rectas son considerados figuras simples terminando por resultar en las operaciones formas de segmentos rectilíneos, donde se presentan todas las potencias examinadas acerca de las magnitudes.

La discusión teórico-metodológica precedente hace comprensible el hecho que su aplicación al mensuramiento del terreno arqueológico siempre resulta la forma de una figura geométrica dada. La 
aplicación de la teoría cartesiana arrojada o volcada al espacio produce segmentos rectilíneos sucesivos que al cruzarse en un punto de línea o encuentro de líneas, configuran ejes coordenados: el eje de las ordenadas y el eje de las abscisas.

En una secuencia de puntos de encuentro lineal, reproducimos las relaciones matemáticas existentes, teniendo como símbolos a letras para el eje de las ordenadas (orden) y números en el eje de las abscisas (dimensión); cada punto de encuentro constituye una coordenada de los puntos del terreno, así como eje de control de las distancias, las que pueden seguirse alargando al infinito (largo: longitud; ancho: horizontal).

Mensurada la zona arqueológica en base al sistema de coordenadas cartesianas explicadas, pasamos a las excavaciones arqueológicas. Tales trabajos alcanzan al presente la apertura de 24 cuadrículas $(10 \mathrm{~m} . \mathrm{x} 10 \mathrm{~m} . \mathrm{c} / \mathrm{u})$, siendo el 95\% del total de las excavaciones que el edificio requiere. Estos trabajos han producido la extracción de unas 20 toneladas de escombros, erradicados por la Municipalidad en el mes de Mayo (1991) por 241 volquetadas, los cuales realizaron otros tantos viajes portando un promedio de $8 \mathrm{~m}^{3}$ de capacidad de carga. Desde Mayo (1991) al presente ya están amontonadas otras 10 toneladas de escombros como resultado de la continuidad de los trabajos "in situ".

Debemos explicar que llamamos escombros a los materiales de relleno ocurrentes en todas las cuadrículas de excavación: tierra, terrones, grava, cantos rodados, estiércol de ganado europeo, etc., cubrían las cuatro secciones del monumento.

\section{El Valle de Lima (1000-1535 D.C.)}

El valle de Lima, ubicado en la costa central del Perú, pertenece a la cuenca del río Rímac, cuyas características físicas son cambiantes a lo largo de su trayecto, desde la quebrada alta hasta sus tierras llanas próximas al litoral del Pacífico.

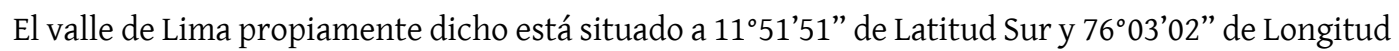
Oeste. Las características geográficas y ecosistémicas de este valle se encuentran relacionadas a la naturaleza y los procesos de ocupación cultural, ya que sobre su gran manto de conglomerado aluviónico ocurren las ocupaciones arqueológicas, coloniales y republicanas.

La fuente de vida importante de este valle es el Río Rímac, cuyas nacientes las encontramos en las cumbres glaciares de los alrededores de la laguna llamada Quiullacocha donde nace el río Yuracmayo a 4,900 m.s.n.m., cuyas coordenadas son $11^{\circ} 51^{\prime} 18^{\prime \prime}$ de Latitud Sur y 7601'12" de Longitud Oeste. Se trata de un panorama de glaciares escarpados; Glaciar Paccha con 5,530 m.s.n.m.; Glaciar Norman con 5,500 m.s.n.m.; el Pico Tatajaico a 5,330 m.s.n.m. y el Glaciar Antachame con 5,715 m.s.n.m. El Yuracmayo (río Blanco) recorre los parajes altos de la cuenca hasta su unión con el río Chicla, prácticamente su afluente alto: en el área de Ticlio existen pequeñas lagunas ubicadas entre 4,800 á 4,900 m.s.n.m. cuyas aguas vierten en forma de pequeños riachuelos por los pliegues rocosos que los conducen hacia abajo para aumentar el caudal naciente del río Rímac, el cual ya tiene buen volumen en Chicla: desde esta unión se torna rumoroso. Pedregoso y turbulento pasa el Infiernillo; entre altas paredes rocosas recorre Chaupichaca, erosiona los colmatajes de lodo y cantos rodados en Tamboraque y luego formando pequeños meandros entre los derrubios baja para atravesar Tornamesa, San Bartolomé y Retamas entre ralo monte ribereño, de allí el largo lecho de transporte colecta aguas del río Santa Eulalia por su margen derecha en la localidad de Mama (Ricardo Palma); aguas bajo el cono deyectivo se va abriendo al valle medio (Chosica, Chaclacayo y Ate Vitarte): después aparece la amplitud del valle bajo y el río discurriendo por su ámbito septentrional hasta desembocar a dos kilómetros al norte del Callao. 
Consecuentemente, la cuenca está formada por las estribaciones orogénicas que lo encajonan y delimitan, su río, el valle, los desiertos aledaños con sus "lomas" y los asentamientos humanos que vienen desde muy antiguos tiempos.

Desde perspectivas ecosistémicas el valle bajo de Lima se encuentra en región sin lluvias, rodeado de geomorfología desértica y áreas húmedas de "lomas", debido a las modificaciones climáticas ejercidas por el fenómeno de la inversión térmica, el cual evita las precipitaciones pluviales pese a que se encuentra ubicado dentro de los límites de la región tropical. Por tal razón es evidente que en una región desértica la irrigación haya sido el factor decisivo para el aprovechamiento de las tierras llanas y el consiguiente asentamiento de secuentes y variadas poblaciones, las que a la llegada de los españoles conformaban demografías de patrón concentrado emplazadas en distintos rumbos del valle.

En cuanto al nombre del valle podemos precisar la siguiente secuencia:

1. Siglos XI-XV: Limamarka, nombre de la nación intermedio tardía que ocupaba el centro del valle bajo. Se desconoce si el río tenía nombre, pero en su confluencia con el río Chacalla (Santa Eulalia), era llamado río Mama, según la fuente etnohistórica.

2. Siglos XV-XVI: Rímac, dominio del Tawantinsuyu.

3. Colonia: Lima, nombre del valle y la ciudad.

4. Siglos XIX-XX: Rímac, nombre del valle y Lima el de la ciudad.

5. En la actualidad: Lima nombre del valle y la ciudad. Rímac, nombre del río.

Los cronistas españoles (Pedro Cieza de León, Bernabé Cobo, Fray Antonio de la Calancha, el anónimo Lusitano del siglo XVII, etc.), los cronistas andinos, así como los viajeros del siglo XIX, escribieron cortas referencias acerca de la presencia de montículos arqueológicos diseminados por el valle; en realidad informan sobre concentraciones arquitectónicas de próxima vecindad hacia el centro del valle bajo (actuales distritos de Pueblo Libre, Magdalena del Mar, Breña, Jesús María, El Cercado de Lima, Lince, La Victoria, parte de San Isidro, parte de Surquillo, Miraflores, San Borja y San Luis).

Los estudios realizados durante la ejecución de este Proyecto, comprueban la presencia de regular cantidad de montículos, cuadrángulos, edificios, muros, caminos, etc., en el área señalada perteneciente a distintos períodos arqueológicos, pese al intensivo proceso de urbanización que nunca ha planteado planes de reserva o preservación para los monumentos del valle.

\section{El Sitio Arqueológico}

Cincuenta años atrás (1960), antes de la gran expansión urbana de la ciudad, muchos monumentos arqueológicos del valle de Lima alzaban sus perfiles en medio de las chacras de cultivo a modo de montículos solitarios. Otros empezaban a ser atosigados por el rápido crecimiento urbano de Lima contemporánea. Una gran parte de ellos ya habían desaparecido debido al tractor de los urbanizadores y vendedores de tierras.

La "Huaca de San Borja" es uno de esos montículos al que los campesinos de la zona circundante llamaban "Huaca de la Luna", por la tradición referente a que en ciertos meses del año, este astro nocturno aparece situado sobre su emplazamiento; como algunos monumentos arqueológicos, este montículo ha sufrido poca predación por sus muros laterales externos, salvo el frente norte, donde expone los mayores destrozos paramentales; el interior en general también presenta deterioros en su 
arquitectura arqueológica, cuyos destrozos se reemplazó por construcciones temporalmente tardías colonial y republicana; la razón es que el edificio siempre estuvo habitado, logrando de esta manera "sobrevivir" a la destrucción total por los sucesivos hacendados propietarios y luego al rápido y desmesurado crecimiento de la ciudad capital.

De tal manera, factores naturales y sociales afectaron su integridad monumental a lo largo de los siglos; destrozos arqueológicos, huaqueos, nuevos usos, rellenos y reedificaciones, abandonos, nuevos rellenos, corral para ganado, cimientos de casa-habitación republicanas, etc., descubrimos durante los estudios.

El sitio arqueológico constituye una sola unidad física con cuatro frentes (sectores) conformantes de una planta básica suavemente trapecial (ver Figura 1); sus medidas tomadas con wincha son las siguientes:
1. Sector norte : 43 metros de largo.
2. Sector sur : 35 metros de largo.
3. Sector este :38 metros de largo.
4. Sector oeste : 39 metros de largo.

La altura máxima del monumento se registra en la cuadrícula C50 (7.90 metros) y corresponde a bases de muros construidos con adobes rectangulares. La altura conservada de los muros arqueológicos es de 6.95 metros, medida en la elevación sur. Por fragmentos de banqueta asociados a las bases de la elevación de muros en la esquina externa noreste y frente oeste, se prueba que el monumento tuvo originalmente banquetas exteriores al menos en tres de sus frentes cerrados (carentes de vano).

El análisis arquitectónico señala que en el frente norte han de haber estado sus accesos desde los comienzos, pues la elevación conservada de los frentes sur, este y oeste no presentan ningún vestigio de ruptura, vano, acceso tapiado, etc.; las excavaciones arqueológicas vienen descubriendo vanos y vestigios de rampas en el frente norte, las que fueron dejadas al descubierto en 1992.

Arquitectónicamente, el monumento en sí mismo, se define como un palacio conformado por tres muros rectilíneos internos ocurridos entre el frente oeste, sur y este a modo de cerco interior más antiguo; por su perfil exterior conserva pintura blanca muraría; internamente se observa una serie de disposiciones constructivas en plantas ortogonales rectilineales a nivel de piso terminado y superposiciones a base de rellenos subyacentes.

Por el exterior de tales muros rectilíneos internos, ocurren de tres a cuatro bloques adosados verticalmente, los cuales están construidos por bloques consecutivos de disposición vertical alterna e intertrabados sus terminales altos rematados en escalonados pequeños. Los bloques consecutivos externos encajan uno al lado de otro en vista horizontal, pero se superponen en el orden vertical y varios ejemplares extienden su masa de barro debajo de los bloques superiores a manera de "amarre" y ajuste murario. Estos dos tipos de arquitectura arqueológica fue visible desde el comienzo de los estudios en el sitio, pero sus interiores estaban totalmente cubiertos, los cuales fueron materia de excavaciones continuadas e intensivas.

\section{Excavaciones y Materiales Arqueológicos}

Las excavaciones arqueológicas se encuentran situadas en el rubro que los arqueólogos llamamos métodos de campo. Tales métodos son procedimientos y operaciones definidas para registrar, 
recuperar y aprehender los datos de los sitios arqueológicos. Así, la excavación arqueológica debe entenderse como la puesta en marcha de la reflexión analítica y crítica. Su finalidad última y concreta es la obtención de información empírica para convertirla en documento de estudio. Documentar un sitio arqueológico significa medir, ejecutar levantamientos topográficos y planimétricos, descubrir y recuperar materiales de superficie, hacer detalladas descripciones de sus elementos constitutivos y asociados, observar el entorno y registrar fotográfica y fisiográficamente las características ecosistémicas; la excavación arqueológica propiamente dicha se ejecuta "in situ" y consiste en roturar la tierra (terreno, montículo o ambos) para descubrir sus contenidos culturales (Foto 1).

La excavación arqueológica es un método destructivo, por eso mismo irrepetible e irreversible; de allí que el trabajo importante del excavador sea el de registrar acuciosamente todo el proceso en realidad del contexto.

En San Borja, las excavaciones arqueológicas son la base fundamental y la principal técnica para obtener datos empíricos, recuperar materiales culturales físicos y definir los estratos correspondientes según la Ley de Steno (Ley de la Superposición), así como la estratificación pertinente. La superposición de estratos constituye a su vez la base del principio de datación relativa, instrumento indiscutible de cronología relativa. El estrato es una o varias capas de materiales arqueológicos, cuyos contenidos asociados entre sí, están depositados en capas de estratificación vertical. La estratigrafía la definimos como aquella sucesión de estratos superpuestos en que los inferiores son más antiguos que los ubicados en posición superior hasta la superficie dada. Ésta se analiza muy bien en un perfil: el perfil es cualesquiera de los lados de las cuadrículas de excavación, cuya secuencia vertical física sirve para control de datos estratigráficos; el perfil se analiza y "lectura" durante todo el proceso de excavación. Por último, la estratificación es una secuencia vertical de estratos indicativa de ocurrencia alterna o sucesiva de fases o períodos témporo-sociales de gente ocupando el sitio y connota diferencias de tiempo lo cual permite hacer interpretaciones culturales diferenciales.

En San Borja, las excavaciones se iniciaron después del levantamiento topográfico y cuadriculación con acotamiento de todo el terreno en base a ejes coordenados. El resultado de este trabajo fue cuadrículas de 11 metros incluidos 2 metros de bordo en ejes de simetría reticular (Foto 2).

La excavación de arriba hacia abajo distingue y define el nivel de excavación, contenido de capa y permite aislar el estrato cultural correspondiente. Los estratos son representativos de ocupaciones ocurridas en el monumento desde su construcción hasta el abandono definitivo. Esta sucesión de ocupaciones ocurridas en el tiempo, en términos sociales, constituye el proceso activo de continuidad, alternancia o abandono del sitio e incluso su reocupación cultural. En teoría implica fundación, vida activa, funciones, problemas compulsivos, relaciones interactivas, contactos interculturales, impactos sociopolíticos desde el exterior, etc., hasta el abandono por factores varios y después, la reocupación, marcadora de cambios de tenencia en el manejo y funciones del sitio.

Las cuadrículas excavadas son las siguientes:

1. A10, A20 - no han sido excavadas, pues ocurren en el área plana exterior.

2. A30 - excavada en su totalidad.

3. A40 - excavada en un $90 \%$.

4. A50 - excavada en un $90 \%$.

5. B10 - excavada en su totalidad. 
6. B20 - excavada en su totalidad.

7. B30 - excavada en un $70 \%$.

8. B40 - excavada en un $70 \%$.

9. B50 - excavada en un $50 \%$.

10. C10 - excavada en su totalidad.

11. C20 - excavada en su totalidad.

12. C 30 - excavada en un $90 \%$.

13. C40 - excavada en un $50 \%$.

14. C50 - excavada en un $50 \%$.

15. C60 - excavada en su totalidad.

16. D20 - excavada en un $50 \%$.

17. D30 - excavada en su totalidad.

18. D40 - excavada en un $70 \%$.

19. D50 - excavada en un $50 \%$.

20. D60 - excavada en su totalidad.

21. E20 - excavada en su totalidad.

22. E30 - excavada en un $70 \%$.

23. E40 - excavada en su totalidad.

24. E50 - excavada en su totalidad.

Las excavaciones de las cuadrículas mencionadas se ejecutan por "excavación en área" que responde al principio de excavación horizontal y paralelamente aplicando la "excavación en profundidad", al cortar la tierra cobertora del montículo en disposición vertical, de allí que cada cuadrícula, a su vez, sea un pozo de control y al mismo tiempo una unidad muestral.

Atendiendo a la estratigrafía arqueológica debemos precisar que actualmente tenemos distinguidas tres secuencias verticales de capas arqueológicas que conforman los tres estratos culturales en San Borja:

\section{Secuencia Estratigráfica A:}

La más antigua, descubierta sobre material geológico, es decir conglomerado aluviónico propio del valle de Lima. Sobre tal basamento encontramos una gran torta de barro muy dura que registra un promedio de 30 centímetros de espesor, encima de la cual se inicia toda la construcción arqueológica (Foto 3). Prácticamente es un tendal arcilloso compacto sobre el que descansa todo el edificio, constituyendo el fundamento cultural de la secuencia estratigráfica. Tal secuencia lo forman estas siguientes capas: capa J, capa I y capa H; sus niveles excavados exponen distintas características, constituyendo cada una de ellas una verdadera unidad temporal.

Capa J: Los muros y pisos de las alzadas arquitectónicas en el frente norte se hallan directamente 
asentados en la torta basal reseñada; hacia los sectores interiores se observan espacios rectilineales delimitados por muros rectos y compartimientos rellenados, cuyas paredes han alcanzado altura sobre los 7 metros. La evidencia está otorgada por la planta ortogonal del edificio cuyo trazo rectilineal de los paramentos están enlucidos con frotado duro. El material constructivo es adobón (prácticamente encofrado en barro). Este adobón fue tratado percutidamente, para hacer que el enlucido alcanzara dureza y lustre en óptica natural, según las improntas superficiales; los muros con tal enlucido, al parecer, sufrieron grandes destrozos, pues los terrones son registrados como material de relleno abundante en los sectores internos excavados. En base al estudio de los rellenos con terrones de tales características, lentes de cantos rodados y grava, tierra y arena sueltas en asociaciones contextuales, la capa corresponde temporalmente a la ocupación cultural tardía del Horizonte Medio (900-1200 d.c.). La cerámica arqueológica es fragmentada; se le encuentra entre los rellenos y proviene de fuera del monumento (cerámica llana y unos pocos fragmentos pintados de estilo Lima tardío).

Capa I: Distinguida sobre la presente Capa J: su excavación se ejecuta en función de establecer la asociación contextual con los muros colaterales adyacentes a los niveles céntricos descubiertos en el área central del edificio, esto implica revisar minuciosamente las características del contenido de la capa (terrones, tierra suelta, grava y escasa basura vegetal) en relación directa con la arquitectura que se descubre "in situ", pero además, el análisis tipológico de los paramentos se extiende a comprender la cronología de los muros construidos por el sistema de adosamientos consecutivos por los flancos externos de bloques trapezoides y/o triangulares, conformantes de los frentes arquitecturales externos.

De los análisis arquitectónicos y contrastación de características tipológicas realizadas entre los muros descubiertos confrontados, establecemos el carácter diferencial arqueológico de los muros construidos a base de bloques por el sistema de adosamientos consecutivos exteriores -cubriendo verticalmente a los antiguos muros rectilineales- por los cuatro frentes del monumento (Foto 4, Foto 5).

Cronológicamente corresponden al período Intermedio Tardío (1100-1470 d.C.). Examinados los terrones componentes de los rellenos de esta capa se comprueba que provienen del destrozo de secciones murarias construidas por bloques: contrastamos barro constitutivo del adobón, su acabado exterior, la forma constructiva a base de bloques trapeciales de disposición entrabada y el uso de grava y cantos rodados para los rellenos interiores -entre muros- pero también entre pisos y los rellenos bajo apisonados (Foto 6, Foto 7). Se constatan muchos destrozos en los muros construidos por bloques a lo largo de la historia del monumento tanto en los tiempos arqueológicos como durante la Colonia y República.

Entre los rellenos internos descritos ocurren abundantes fragmentos de cerámica arqueológica llana, y figurinas fragmentadas, no siendo tal alfarería propia del monumento, sino proveniente de los derredores.

Material arqueobotánico, osteológico humano disperso y paleoetnozoológico encontramos asociado a la fragmentería; todos estos materiales culturales son coetáneos a los rellenos, no son propios del monumento, proceden del exterior y han sido vertidos en la República (siglos XIX y XX).

La capa J y la capa I tienen un metro de espesor.

Capa H: Corresponde a la ocupación Tawantinsuyu del sitio (1470-1535 d.C.); las evidencias son unos pocos fragmentos de cerámica estilo Cusco Polícromo, además de los datos de contexto ocupacional en general del valle por la expansión cusqueña e inferencias etnohistóricas documentales. No hay arquitectura Tawantinsuyu en el monumento. La gente que vivía en el sitio bajo el dominio del 
Cusco habría sido administrada desde Mateo Salado, sede de la residencia curacal intermedio tardía de la Nación Lima en el valle (Limamarka). En este punto es evidente la identidad constructiva de la arquitectura a base del sistema por adosamientos consecutivos de bloques trapezoides ocurrentes en forma masiva y volumétrica en Mateo Salado (ubicación: Plaza de la Bandera - Pueblo Libre), donde se ha estudiado que tuvo asiento principal el pueblo arqueológico intermedio tardío llamado Limamarka, con la misma tipología arquitectónica de San Borja Norte.

Así, el monumento de San Borja (perteneciente a la Nación Lima intermedio tardía) prolonga su existencia durante el dominio del Cusco en el valle (Horizonte Tardío), hasta el arribo de los españoles los años de 1533, 1534 y 1535, a partir de los cuales se quedaron definitivamente en el país.

\section{Secuencia Estratigráfica B:}

Correspondiente a ocupaciones sociales ocurridas en la Colonia. Por contexto etnohistórico se comprende que los españoles se instalan definitivamente en Lima hacia 1535. En San Borja Norte no hemos obtenido material europeo de los siglos XVI-XVII y XVIII quizá porque hay evidencias que la ocupación siempre fue por gente andina.

Problemas compulsivos y belicosos drásticos ocurridos en el país entre 1535-1545 (insurgencia de Manco Inca con sitio y ataque a Lima, guerra entre los españoles, captura de hombres andinos para ser utilizados como vanguardia de las mesnadas españolas, etc.) habrían causado abandono del lugar por estos años sumamente confusos para las poblaciones impactadas por la irrupción violenta de los españoles. Hay noticias que para la defensa de Lima durante el sitio ejecutado por Quisu Yupanqui, Francisco Pizarro y otros españoles convocaron a la población andina de Lima (de todos los sitios ahora arqueológicos del valle) obligándolos a su defensa conjuntamente con ellos. Las excavaciones en San Borja señalan ciertos años de abandono a nivel de piso arqueológico subyacente, probablemente producido por los acontecimientos reseñados. No hay huellas, ni material de ocupación europeo. Sin embargo, el análisis de la superficie de los pisos, muros laterales de los compartimientos y plataformas con escalera subyacentes muestran nueva ocupación andina sin aparentes modificaciones.

Capa G: Es la que se encuentra en relación directa con los pisos y muros arqueológicos subyacentes a seis metros de profundidad; presenta el espesor de un metro como máximo, según los rellenos estudiados. No hay huellas de estiércol de animales europeos.

Los grumos y terrones conformantes del relleno al parecer provienen de terrenos de cultivo y no de muros desplomados.

Hay restos de fogones, segmentos quemados en los pisos como resultado de la migración o reubicación de los fogones, así como presencia de vegetales bien conservados; corresponden a las primeras ocupaciones andinas que re-usaron el edificio después de la invasión española. Esta gente no dejó cosas, simplemente abandonó el lugar practicando el mismo silencio y precariedad con que llegó.

Capa F: Corresponde a una ocupación relativamente prolongada, probablemente también en el período colonial; todas las evidencias de contexto indican que después del abandono anterior (Capa $\mathrm{G}$ ) el edificio sufrió remodelaciones con rellenos, muros y apisonados (Cuadrículas C20, C30 y C40 a los $5.50 \mathrm{~m}$. de profundidad).

Se encuentran en estudio dos pequeños vanos descubiertos en C30 y B30 respectivamente para establecer su cronología, difícil de precisar porque parecen abiertos después de la construcción arqueológica de los muros en que se encuentran. 
El estudio de los rellenos arroja datos acerca de las asociaciones de terrones con improntas estriadas (al parecer revoque de techos construidos con cañas); otros terrones pequeños llevando varillas de helecho como armazón (no tiene contexto en el sitio), soguillas de enea que envuelven manojos de caña brava, trozos de carrizo (europeo), cintas de enea trenzada y pequeños textiles (fragmentos) de manufactura andina desechados como basura; tallos, pancas y corontas de maíz son contenidos bajo los apisonados. A nivel de superficie apisonada asociada a los contenidos descritos, registramos estiércol de oveja paralelamente a la de camélido, lo mismo que sus correspondientes huesos sueltos. Los ocupantes de esta capa eran agricultores, criaban ovinos-caprinos-camélidos y vivían permanentes en el monumento haciendo vida cotidiana.

En el caso de la arquitectura notamos que resanan rajaduras y huecos de los muros, remodelan apisonados que se deterioran por el uso y tienen acceso por el frente norte.

Capa E: Al final de la Capa F distinguimos un corto tiempo de abandono y descuidado re-uso del sector norte del monumento; al parecer por este tiempo viviendas ubicadas en dicho sector son abandonadas. En el interior del monumento se han descubierto apisonados sobre los pisos arqueológicos; dos grandes huecos de morfología cónica, evidentemente para colocar grandes ceramios, con otros dos pequeños anexos alternados encontramos a nivel de piso terminado; gran cantidad de sinchos de enea trenzados, tallos, pancas y corontas de maíz, soguillas rotas, así como restos de horcones de madera incrustados en el piso arqueológico subyacente y torta de barro apisonada por re-uso, etc., descubrimos durante las excavaciones de esta cuadrícula (D20).

Se construye una escalinata de tres escalones que accede a una plataforma otorgante de articulación al nivel alto; al pie del muro sur interior en el recinto R-1 construyeron un poyo que habría funcionado para dormir.

El análisis contextual de esta capa muestra ocupación intensiva del monumento. Se ejecutan construcciones y remodelaciones internas como venimos describiendo: en las cuadrículas B40-C30 construyen grandes escalinatas con orientación este-oeste de sus cuatro peldaños; cubren pisos arqueológicos mediante rellenos a base de terrones, basura vegetal, soguillas y cinchos trenzados de enea, pancas, corontas y tallos de maíz, maní, pacae, etc., para obtener niveles con superficies planas selladas por tortas de barro y apisonados delgados resquebrajados. Huellas de uso continuo notamos en todo el ámbito. Sobre los rellenos de poco espesor ( $0.50 \mathrm{~m}$. promedio) construyen plataformas adosadas al piel del muro transverso sur de $\mathrm{C} 30-\mathrm{C} 40$ y al costado izquierdo de la gran escalinata citada. Durante el proceso de excavación se registran vegetales de chacra, fragmentería de cerámica llana venida del exterior con los rellenos, etc. No encontramos cerámica propia del monumento.

Esta capa descrita se presenta transicional entre el período Colonial tardío y la República.

\section{Secuencia Estratigráfica C:}

Ocurren materiales, remodelaciones y construcciones adicionales en el siglo XIX y XX (República).

Capa D: Corresponde al re-uso urbano marginal del sitio y grandes excavaciones clandestinas. Es posible que al nuevo abandono del sitio, este haya empezado a ser huaqueado sin misericordia durante algunos años. La arquitectura transicional de la capa E presenta huaqueos, roturas y daños causados por abandonos. Sin embargo, algún ocupante bajo la dirección del hacendado del sector habrían decidido enterrar sectores a la vista, huaqueos y muros rotos, portando material de desplome y escombros del mismo monumento y otros aledaños hasta los sectores interiores para cubrirlos. Terrones, tierra, grava y cantos rodados, casi exentos de basura orgánica cubren los espacios internos 
y sectores depredados. Sobre tales rellenos se construyen muros de tapia en las secciones bajas del frente norte y sección alta del monumento; algunos basamentos de adobes rectangulares adheridos a las bases de muros del frente norte asociados a estaca plantada, indican casa de gente que está criando ganado caballar por mucho tiempo, pues las capas de guano excavadas en B20, B30, A30, A40 tienen más de 2.00 metros de espesor. Algunos segmentos de los rellenos descritos presentan adobes rectangulares rotos desechados, inclusive con huellas evidentes de quemados o afectados por el fuego. Rastrojos de chacra abundan: tallos y pancas de maíz, restos de corontas, hojas y cáscara de pacae, carrizo, lúcuma, etc.; la cerámica de rotura antigua es una asociación constante. En la parte alta del monumento se ejecutan varias remodelaciones echando barro para cubrir construcciones anteriores, enterrar compartimientos, tapar pasajes, remodelar espacios abiertos, etc. Son comunes los muros de una sola cara, cuya capa de barro final extiéndese a manera de piso sellando rellenos subyacentes, cubren secciones constructivas precedentes, etc.

Analizando los contextos y huellas de actividades relacionales, nos percatamos que predominan los indicadores agrícolas y ganaderos en derredor del sitio.

Capa C: Entres ésta y la capa D precedente se nota una ocupación continuada hacia la esquina alta sur-este a base de construcciones en tapial, las que están cimentadas sobre casi cuatro metros de relleno conformado por terrones compactos. Esta ocupación construye una casa de planta rectangular y al parecer también se encuentra ocupada la esquina noreste -al pie de muros altos al interior- donde se identifica la casa subyacente que al ser abandonada o cambiar de uso se convirtió en corral de porcinos. Este es tiempo en que está ocurriendo grandes destrozos en el frente norte.

En la sección alta central del monumento encontramos la presencia de una casa grande construida con adobes de $0.52 \times 0.23 \times 0.12 \mathrm{~m}$. promedio confeccionados en gavera. Los rellenos subyacentes lo constituyen tierra suelta, terrones de adobón y lentes de grava; sobre ellos tendieron una torta de barro (entre $0.10 \mathrm{a} 0.15 \mathrm{~m}$. de espesor) para hacer pisos de por lo menos 6 habitaciones, cuyos cimientos conservados tienen entre 4 y 2 hiladas de adobes.

La construcción de esta casa enterró a la anterior de muros de tapial (Capa D); el estudio de su relleno subyacente precisa $85 \%$ de tierra, terrones, residuos vegetales de chacra, etc., y $15 \%$ de grava y cantos rodados. En el sector externo lateral suroeste del monumento, entre el relleno, descubrimos una hoja de periódico fragmentada del diario "La Prensa" del Domingo 3 de Octubre de 1915, impreso por el sistema de tipografía. Es evidente que al depositarse el periódico, el sector constructivo del tapial se encontraba en funciones; por tanto, el fragmento de periódico con su fecha indicada, muestra tiempo de 1915 para atrás; en consecuencia, la casa de adobes rectangulares construida sobre rellenos que entierran a los muros de tapial, es edificada después de 1915.

Es definitivo que los muros de tapial subyacentes descubiertos por excavaciones en las cuadrículas D40, D50 y C50 son base de la casa de adobes rectangulares descubierta en las cuadrículas D30, D40, D50, C40 y C50.

Entre los rellenos anotados líneas atrás se registra material orgánico:

- Vegetales de chacra: frijol, maní, maíz, calabaza, achira, lúcuma, pacae, hierbas, etc.

- Huesos: de ovino, caprino, camélido, equino y aves, etc.

- Moluscos: choro, macha, chanque, etc. 
Se trata de restos orgánicos aleatorios asociados y entremezclados a la tierra y terrones, pedazos de adobes rectangulares, etc., que ocurren bajo las casas republicanas descritas.

La gente que está ocupando esta capa parece más ganadera que agricultora, pues todo el monumento en sus secciones altas y parte baja del frente norte, está cubierto por gran cantidad de estiércol. Los perfiles de las cuadrículas B20-B30-A30-A40, miden de dos a tres metros promedio en la vertical y 50 metros de largo (cuadrículas B10, B20, B30, A30, A40, A50), cubriendo edificaciones deterioradas, como ya se ha descrito.

Capa B: Corresponde a niveles de estiércol apisonado y trozos de adobes esparcidos entre las capas de guano. El estiércol está duramente apisonado, conformando niveles superpuestos de variado espesor (desde $0.10 \mathrm{~m}$. hasta $0.30 \mathrm{~m}$.).

En el frente norte, al pie del monumento los niveles superpuestos de estiércol alcanzan hasta 70 $\mathrm{cm}$. con huellas de quemados, adobes, adobes rotos y lentes de ceniza, todos republicanos.

En la sección alta central (cuadrículas D30-D40-D50-C50) el estiércol apisonado fue registrado directamente acumulado sobre el piso de la vivienda republicana de adobes rectangulares, la misma que se descubrió enterrada por tales niveles de guano. Aquí los niveles de guano acumulados alcanzan 30 centímetros de espesor y corresponden al re-uso del monumento después del abandono de la casa de adobes rectangulares (antes de 1950 d.c.).

Todo indica que al ser abandonada la vivienda, las secciones altas, las partes bajas del frente norte, así como los frentes este y oeste -al pie de sus muros- fueron convertidos en cobertizos y criaderos de semovientes.

En este tiempo se practica dos grandes huaqueos en el sitio. Uno hacia el sector noreste (cuadrículas B40-B50) y otro en la parte céntrica del frente oeste que afectó a los gruesos muros perimetrales amontonando los escombros en la parte baja exterior conformando un plano inclinado que sirvió de acceso posterior.

Capa A: Corresponde a la superficie. Su espesor es variable. No distinguimos niveles definitivos. Contiene tierra suelta polvosa, basura actual y coprolitos humanos en varios sectores, sobre todo en aquellos cercanos a muros. Existen suaves depresiones que denuncian huaqueos en los últimos años (1988, año del comienzo de los trabajos en el sitio). Visualizamos sectores de ceniza y tierra quemada. Emergen algunos muros entre la tierra. En las partes bajas de los frentes norte y sur descubrimos raíces de carrizo, yerbas y arbustos que crecieron espontáneamente rodeando al monumento.

En el caso del frente norte cobramos entre las raíces una hoz de fierro, con la que probablemente se cortaba pasto para los animales que todavía eran amarrados en la cumbre hasta la década de 1950.

En su sección alta encontramos rastros de chozas confeccionadas con ramas y esteras de carrizo, probablemente para servir de refugio a guardianes de las chacras de algodón y/o uvas, en la antesala a la urbanización incrementada a partir de 1960.

\section{Los Materiales Arqueológicos}

Los materiales recuperados en las excavaciones están constituidos por aquellos encontrados en las áreas internas y externas, los rellenos arqueológicos, así como en contextos de ocupación republicana. A continuación, presentamos el listado de los materiales recuperados: 
1. Material Cerámico $.7,000$ fragmentos.

De este total se cuenta con seis mil fragmentos de cerámica arqueológica, algunos de los cuales presentan decoración lineal en negro, blanco y rojo intermedio tardío. De este material 3 piezas corresponde a estatuillas o figurinas incompletas del estilo Ichimay. Una gran cantidad está dada por fragmentería que corresponde a bordes, cuerpo, asa, pedestales o bases. Otros fragmentos corresponden a ollería, cántaros medianos y ánforas cercanas al metro de altura.

Los fragmentos correspondientes a la época republicana están dados por aquellos que presentan vidriado verde, azul, blanco, marrón o ligeramente violeta. Se cuenta con algunos fragmentos de ollas del siglo XX con impregnaciones de ollín pertenecientes a los últimos años de reocupación del sitio.

2. Material Óseo 300 especímenes.

El material óseo está constituido por huesos de camélidos (básicamente llama), vacunos, equinos, caprinos, ovinos, cánidos y aves de corral. En las cuadrículas A40 y B20 se han recuperado cornamentas de ovino y vacuno en estrato republicano.

3. Material Malacológico. 120 especímenes.

Está constituido por12 variedades de moluscos de nuestro litoral, siendo el Spondilus Princeps el único que proviene del Golfo de Guayaquil (Ecuador), región ecológica donde vive este molusco bivalvo de color rojo y que en el antiguo Perú cumplió fines rituales.

4. Material Orgánico. .150 muestras.

Hemos recuperado muestras arqueológicas y plantas silvestres o de canto de chacra. También se han tomado muestras para análisis de polen. Entre los rellenos internos del monumento (República) se recupera abundante soguilla y sinchos trenzados en enea (totora).

5. Material Lítico 12 ejemplares.

Lo constituye dos morteros de piedra granítica uno de ellos fragmentado), cuatro pulidores, un batán y su respectivo "chungo" o piedra de moler. Además recuperamos piedras con huellas de uso y otras fracturadas provenientes de contextos de actividad republicana.

6. Metales. 5 objetos.

Se han recuperado hasta la fecha tres herrajes de caballo, una moneda (un centavo) y una hoz de fierro. Esta hoz corresponde a las actividades agropecuarias republicanas desarrolladas alrededor del sitio; se la descubrió asociada a raíces y tallos cortados de carrizo y hierbas cubiertas de tierra en el sector céntrico bajo el frente norte (cuadrícula A30).

7. Arquitectura .5 fases constructivas.

Hasta la fecha el descubrimiento más importante en el sitio lo constituye su arquitectura. Sin duda, el conocimiento pormenorizado, identificación cronológica, distinción estilística y funciones constituye un aporte de gran valor para la comprensión del fenómeno urbano en el valle de Lima para tiempos arqueológicos tardíos y establecer las reocupaciones ocurridas en los monumentos durante la Colonia y República, así como las remodelaciones que sufrieron.

Las investigaciones arqueológicas han diferenciado cuatro períodos arquitectónicos en la Huaca San Borja: 
4. Arquitectura de la República: ocupación urbano-marginal (siglo XIX y siglo XX).

3. Arquitectura Colonial Tardía: reuso del edificio durante el siglo XVIII y principios del siglo XIX.

2. Arquitectura Intermedio Tardía: (1100-1470 d.c.), a base de bloques intertrabados de morfología trapezoide.

1. Arquitectura tipo Cajamarquilla (900-1000 d.C.), extendida al valle bajo en el Horizonte Medio de la Costa Central.

1. Los adobes rectangulares.............todos republicanos.

- $\quad$ Adobe Trapecial A (58 x 26 x $14 \mathrm{~cm})$ : descubierto en la cuadrícula B30 subyacente a apisonamiento de estiércol y tierra compactada; fueron hechos en gavera y por un lado muestran improntas de dedos del labrador adobero.

- Adobe Rectangular A1 (42 x 30 x $10 \mathrm{~cm})$ : descubierto en contexto de relleno al interior de las cuadrículas C30, D30, D40; uno de ellos fue descubierto formando el relleno interior de un muro de tapial de una sola cara (cuadrícula D50). Es evidente que el tapial es republicano, lo mismo que el adobe utilizado como material de relleno; tales adobes fueron confeccionados en gavera, pues por uno de sus lados muestra la consabida impronta de dedos.

- Adobe Rectangular A2 (47 x 26 x $9 \mathrm{~cm})$ : descubiertos en relleno al interior de la cuadrícula $\mathrm{C} 30$ y a 2 metros de profundidad con respecto a la cota de la coordenada; fueron hechos en gavera.

- Adobe Rectangular B (52 x 23 x $12 \mathrm{~cm})$ : encontrados conformando muros de vivienda republicana en la cima del monumento (cuadrículas D30, E30, D40, D50, C40, C50). Los mismos tipos de adobes son descubiertos en la cuadrícula B20; también fueron confeccionados en gavera y se asocian a niveles de estiércol de équidos y ovinos.

- Adobe Rectangular C (44 x 19 x $13 \mathrm{~cm}$ ): identificados conformando subdivisiones murarias en la casa de adobe de la cuadrícula B40; confeccionados en gavera, tienen acabado pulido y son escasos en el sitio.

1. Otros hallazgos......................(ofrendas shamánicas actuales).

En diversos puntos del monumento se han desenterrado pequeñas ofrendas de naturaleza shamánica o curanderil cuyo significado está dado por creencias que aún se conservan en los estratos populares de nuestra población actual. El más importante de estos hallazgos lo constituye la ofrenda de un cuy asociado a hojas de coca, huairuro, pirita, hierro nativo, cuti-cuti (espiral vegetal), semillas de uña de gato, clavel, fruto de keropaque y un cigarro. La ofrenda ha sido recogida en una vitrina especial.

Otros hallazgos inusitados fueron las deposiciones de cadáveres republicanos hacia el sector noreste del monumento; estaban vestidos con ropa de campo regularmente conservados:

a. Un párvulo dentro de una caja de tablas de madera rústica, enterrado al pie interior de la esquina noreste.

b. Un niño enterrado entre tablas de sauce y pino, envuelto por trapos rústicos y llanos.

c. Entierro de un cadáver junto al paramento interior noreste tapado con trapos y un costal de yute. Se encuentra "in situ". 


\section{ANÁlisis de la InFormación ARQueológica}

En 1896, el Dr. Max Uhle se encontraba trabajando en la zona arqueológica de Pachacamac (valle de Lurín). Hacia comienzos de siglo (Uhle, 1903) aplicó por primera vez el nombre de "Proto-Lima" a una serie de materiales arqueológicos provenientes de sus excavaciones en este gran sitio ubicado a 30 kilómetros al sur de Lima, así como a otros similares obtenidos en sus reconocimientos por el valle de Lima.

Los arqueólogos norteamericanos Alfred L. Kroeber, Ana Gayton y Wendell C. Bennett siguieron en una u otra forma la terminología del maestro alemán. En 1935 el Dr. Pedro Villar Córdova propone llamar "Cultura Lima" -representada por la cerámica "Nievería"- a tales materiales que ya estaban apareciendo en varios contextos asociados en tumbas y altas pirámides de perfiles escalonados construidas a base de adobitos modelados a mano. El peruano Jorge C. Muelle explicaba utilizando los nombres de "Proto-Lima"/"Nievería" para la cerámica Intermedio Temprana de Lima. El Dr. Tello llama "Pachacamac" a los materiales intermedio tempranos de esta zona arqueológica (1942).

Trabajos arqueológicos diversos plantean para los materiales arqueológicos Intermedio Temprano de Lima, unas veces como "Cajamarquilla" y "Nievería” (D’Harcourt, 1922), otras oportunidades sólo prefieren nombrarlos "Nievería” (Mejía Xesspe, 1938), Uhle en 1910 menciona el término "Interlocking”, ratificado por Kroeber en 1954; el ecuatoriano Jijón y Caamaño, 1949, especifica el término "Maranga" con relación al monumento del ex - fundo Aramburú; unos años después, el norteamericano Louis Stümmer prefiere usar este término para sus trabajos en los valles de Lima y Chillón los años 1954, 1957 y 1958; paralelamente el arqueólogo cubano Ernesto Tabío introduce el nombre de "Playa Grande" para bautizar a sus materiales intermedio tempranos obtenidos en las excavaciones de Playa Santa Rosa (Ancón) los años 1955 y 1957 y publicados en dos tomos (La Habana, Cuba, 1965); el peruano José Fernández Sotomayor publica en 1960 un estudio tipológico-estilístico dedicado al "Estilo Maranga", distinguiendo tres tipos: Maranga A, Maranga B y Maranga C.

En medio de tal diversidad terminológica Thomas Carl Patterson, arqueólogo norteamericano, decide nominar "Lima" a los materiales arqueológicos intermedio tempranos que venía estudiando para su tesis doctoral desde 1964 en los valles de Chillón, Lima y Lurín. En realidad Patterson otorgaba gran peso científico a las propuestas de los arqueólogos estilistas, quienes desde el punto de vista seriativo habían denominado "Interlocking" a la alfarería Intermedio Temprana de la Costa Central, por el diseño geométrico de serpientes, peces o aves entrabadas, frecuentes como motivos decorativos comunes -con ligeras diferencias- a los tipos alfareros llámense Proto-Lima, Nievería, Cajamarquilla/Nievería, Maranga, Cultura Lima, Playa Grande, Pachacamac, Catalina Huanca o Vista Alegre (Stümmer, 1953), o recientemente "Lima" (Patterson, 1967) y otros seguidores. Indudablemente, todo indica que cada sitio establecía un estilo o cultura distinta por aquellos años, lo cual ahora no es pertinente.

Sin embargo, recientemente se ha vuelto a plantear el término "Cultura Nievería" (Shady, 1982) para denominar a la fase final de "Lima" en franco paralelismo con el Horizonte Medio (Menzel, 1968), lo que nos parece temporalmente congruente, según los datos del monumento arqueológico San Borja Norte.

Planteada la problemática expuesta de tal manera, es necesario señalar una cuestión reflexiva fundamental en la aclaración del asunto:

a. El término Proto-Lima fue planteado dentro del esquema "culturas protoides" de Max Uhle (1903), las que éste consideró mayoides; asunto completamente superado en nuestros días. 
b. En los años 1935-1940 se abandonó aquel término y empezó a plantearse la "Cultura Lima" como hemos visto en líneas precedentes (Villar Córdova, 1935).

c. Entre 1942-1945 El Dr. Julio César Tello llama "Pachacamac" a los materiales arqueológicos que registra asociados a arquitectura de adobitos y que tienen el diseño interlocking como principal motivo reiterativamente representado en la cerámica. Tello tuvo razón, pues hoy sabemos que las más antiguas arquitecturas con adobitos están en el valle de Lurín entre 850-500 a.C. y que después se desplazaron a Lima. También el diseño interlocking de mayor antigüedad lo encontramos en los cementerios de Tablada de Atocongo (diseños interlocking geométricos blanco sobre rojo y blanco y rojo sobre pasta naranja paralelo a Lima Temprano).

d. De este motivo y bicromía se avanza al geometrismo tricolor llamado "Pachacamac" por Tello y reiteradamente nombrado "Maranga" y/o "Lima" en el valle de Lima.

e. Hacia 1967 Patterson retoma el término precedente y lo define simplemente como Lima; otros autores lo siguen sin mayor acusiocidad, quizá aceptando el ejemplo de haber quitado el "proto" a Nasca y Chimú desde varias décadas atrás.

f. Es importante precisar pues que la arquitectura de aparejo murario tipo "librero" intermedio temprana (500 a.C.-900 d.C.), cifras cronológicas relativas extremas para la vigencia activa de los constructores con adobitos, es oriunda desde estos siglos, porque la gente del valle conservó el nombre por la vía oral desde estos tiempos hasta el siglo XVI de nuestra era, ya que los españoles registraron el vocablo "Lima" arraigado desde muy antiguo en el valle del mismo nombre con muy larga data.

g. Ahora en las décadas de 1990 al 2010 pensamos que es necesario precisar el hecho fehaciente de la existencia de una nación intermedio tardía realmente llamada Lima, tanto con pruebas arqueológicas como etnohistóricas, la cual estuvo ubicada físicamente en la margen izquierda céntrica del bajo valle de Lima; su arquitectura eleva sus altos volúmenes dentro de los terrenos del ex fundo Azcona, actual proximidad de la Plaza de la Bandera (Mateo Salado). Allí era el centro activo Lima Intermedio Tardío (1000-1470 d.C.) cuyo asiento se conocía como Limamarka. Entonces, sí existe una nación con el nombre de Lima bien ubicada en el espacio y el tiempo, con referencias etnohistóricas abundantes para el Período Intermedio Tardío del Valle de Lima, la cual es continuidad de Lima Intermedio Temprana (nombre del siglo XX).

h. Para concluir tales aclaraciones, precisamos que los materiales Lima I Intermedio Tempranos, se prolongan al Horizonte Medio (esferas de interacción multi-regionales) en los valles de Lurín, Lima, Chillón y Chancay (Puerto de Chancay: Cerro Trinidad), donde se registran adobitos, murales y cerámica con diseños interlocking; mientras que el término "Lima II" debe aplicarse a los materiales y sitios similares recurrentes de la nación Lima Tardía (Lima II) del mismo céntrico bajo valle (1100-1470 d.C.).

En el marco de la arqueología de nuestros días y teniendo en cuenta las investigaciones realizadas, intentamos sustentar la hipótesis referente a que el asiento principal "Lima" no estuvo en el 
"Cercado", sino en Mateo Salado, cuyo territorio estaba rodeado por otras pequeñas naciones a cierta distancia (los etnohistoriadores e historiadores los llaman etnias, curacazgos, cacicazgos o reinos indistintamente) y que se extendió por los predios de los distritos colindantes en un verdadero equilibrio político de buena vecindad.

Buscamos precisar datos arqueológicos y etnohistóricos para alcanzar teoría interpretativa nueva sobre la historia del valle bajo de Lima, pues al presente su información es limitada, incompleta, parcial y/o confusa.

Los estudios arqueológicos y etnohistóricos confrontados permiten señalar la identificación de varias naciones menores cuyos territorios estaban focalizados en el Valle Bajo de Lima, Las Pampas de Zárate y Carabayllo (valle del río Chillón). Tales naciones menores son las siguientes:

1. Zona Arqueológica de Armatambo: el Surco Arqueológico (distritos de Chorrillos, Barranco y Surco actuales), el cual según Bernabé Cobo era el más grande con respecto a otros.

2. Zona Arqueológica de Limamarka: Lima II intermedio tardío; actualmente es llamada Mateo Salado (distritos de Pueblo Libre, Magdalena (Huantille), Breña, El Cercado (Plaza Mayor de Lima).

3. Zona Arqueológica de Limatambo: Lima II intermedio tardío; toda la fuente etnohistórica señala que en el área funcionaba el oráculo del valle y durante el Tawantinsuyu se construyó aquí un tambo para administración y control poblacional como Tambo Tawantinsuyu estuvo en conexión con las otras markas del valle en verdadera interrelación funcional (distritos de San Borja, San Luis, Surquillo y La Victoria).

4. Zona Arqueológica Gualamarka: ahora no existe, pero documentalmente sabemos que ocupaba los terrenos del Country Club de San Isidro, en dirección hacia Puqllana (distritos de San Isidro-Miraflores).

5. Zona Arqueológica Guatikamarka (Guadka): ahora no existe, pero ocupaba terrenos de Carmen de la Legua y Avenidas Colonial y Argentina en dirección a Bellavista del Callao (distrito Carmen de La Legua-Reynoso). También era llamada Guaca la Legua hacia 1900.

6. Zona Arqueológica Makatampu (Conde de Las Torres): tampoco existe al presente, pero los datos señalan un asiento y enorme cementerio en terrenos aledaños a la Avenida Argentina hasta Mirones actuales. Se consideran conexiones de próxima vecindad entre Guadka y Makatampu debido a ciertas similitudes arquitectónicas (distrito del Cercado hacia el noroeste).

7. Zona Arqueológica Malanka/Maranga: se ubica al interior del "Parque de las Leyendas" y la ex - "Feria Internacional", donde se conservan pirámides, plataformas, palacios, un camino monumental, vestigios de estanques para agua, etc., etc. (distritos de Pueblo Libre-San Miguel). En San Miguel todavía encontramos al sitio arqueológico con arquitectura de adobón conocido como Guantinamarka por el Dr. Julio C. Tello (1925). 
8. Zona Arqueológica Mankomarka/Mangomarka: se encuentra en los terrenos del ex fundo Zárate, margen derecha del río Rímac; estaba extendida desde las cercanías de los cerros hacia las pampas de Zárate y el área "El Sauce" con un cementerio grande. Destaca una pirámide escalonada con una rampa frontal curvada (distrito San Juan de Lurigancho).

9. Zona Arqueológica Karawallo (hoy, Carabayllo): destruida totalmente; sin embargo, el sitio arqueológico Naranjal y varios otros sitios del área de Kollique denotan su monumentalidad resuelta en adobón (distrito de Carabayllo).

La arquitectura arqueológica de los nueve sitios estudiada y registrada por los autores del siglo XX, fotos publicadas y descripciones coincidentes con las edificaciones conservadas al presente, evidencian construcciones en adobón $\mathrm{y}$ adobes rectangulares, los cuales conformaron edificios en planta ortogonal, muros verticales de hasta 8 á 10 metros de altura, compartimientos internos caracterizados por espacios cuadrados o rectangulares comunicados por pasadizos articulados por vanos, a veces con dintel $u$ otras veces abiertos por arriba; desde el exterior se accedía por pasajes a patios, desde los cuales se ingresaba a distintos sectores; si se trataba de pirámides los accesos podían ser por rampas o escaleras cuyo dimensionamiento dependía de factores jerárquicos sociales o rituales, así como de procesos políticos de control y relaciones de órdenes administrativos intrasitio y/o extrasitios e intersitios.

\section{El Monumento de SAn Borja Norte}

Nuestras excavaciones en San Borja Norte permiten situar al monumento en marcos temporales relativos con referencia a los siguientes períodos culturales:

5. Período República: ocupación urbano-marginal (siglo XIX y siglo XX).

4. Período Colonial Tardío: Fines del siglo XVIII y principios del siglo XIX.

3. Período Tawantinsuyu (1470-1535 d.C.): Definido sólo a base de pocos fragmentos de cerámica estilo Cusco polícromo.

2. Período Intermedio Tardío (1100-1470 d.c.): Arquitectura construida con bloques imbricados de adosamientos consecutivos al exterior (Foto 8, Foto 9).

1. Período Horizonte Medio (700-1100 d.c.): Arquitectura de muros rectilineales con pintura blanca exterior; plataformas interiores con escalera a nivel de piso bajo, etc., cuyas similaridades las encontramos tanto en el valle medio como en otros monumentos del valle bajo de Lima.

El Monumento Arqueológico San Borja Norte es un único testimonio arquitectónico del Centro Urbano Pre-Tawantinsuyu Limatambo, cuya área construida se desplazaba entre San Borja Norte (Av. Canadá y el antiguo Aeropuerto de Limatambo).

El Monumento Arqueológico de San Borja Norte está construido en adobón (barro apisonado), con muros a base de bloques imbricados por adosamientos consecutivos solucionados en suave talud al exterior; su elevación fue lograda mediante la técnica de rellenar compartimientos internos traslapa- 
dos en verticalidad, teniendo muros medianeros interiores que buzan de norte a sur y de este a oeste, sirviendo de contención a tales rellenos. Ésta arquitectura externa se superpone a la más antigua del horizonte medio en planta y elevación rectilineal. La más visible al exterior es masiva y técnicamente repetitiva en el monumento. Sus perfiles externos sur, este y oeste, así como un remetido frente norte muy destruido, muestran características típicas descritas.

Recurrentemente, entre cuatro a seis muros externos adosados consecutivamente en suave talud, encierran, cercan y delimitan a la unidad arquitectónica interna con verticalidad conservada de siete metros de altura en el ángulo sur-oeste. Los muros con bloques imbricados son morfología arquitectónica intermedia tardía y se correlaciona con arquitecturas arqueológicas de similar tipificación en otras markas paralelas asentadas en distintos rumbos del Valle de Lima, compartiendo técnicas constructivas similares.

El Monumento de San Borja Norte, como arquitectura local perteneciente a la marka Lima entra a formar parte del Tawantinsuyu, sufriendo la gente los trastornos propios del dominio cusqueño. Se impone la institución política y administrativa denominada "Tambo" para funcionar como organismo de control social y político en el orden local.

Respecto a la conversión de sitio monumental para visitas de flujos turístico, como se trata de un monumento arqueológico único del distrito de San Borja, es importante señalar que si se abre al público y se autoriza el ingreso de los visitantes sin control, el edificio de barro (arquitectura delicada) sufriría deterioros, roturas, quiñaduras y pulverización de los muros, plataformas, escaleras y pisos originales, que al presente están bien conservados.

Dado este diagnóstico, para propender a la conservación permanente del monumento estamos planteando un sistema de tres miradores en el exterior:
a. Un mirador en el frente oeste.
b. Un mirador en el frente sur.
c. Un mirador en el frente este.

Cada mirador tendría diez metros de altura, desde los cuales se visualizarían perfectamente los espacios construidos internos del edificio arqueológico.

Instalar el sistema técnico de los miradores permitirá conservar por muchos años las líneas arquitectónicas originarias del monumento arqueológico, evitando su deterioro y desnaturalización, porque no resistiría el tráfico de visitantes y/o el tumulto de estudiantes apretujándose en sus cortos pasadizos o saltando las finas escaleras originales que articulan los desniveles interiores.

El principio técnico es proteger para conservar los perfiles originarios del monumento.

En cuanto al descubrimiento de la arquitectura Lima II Intermedio Tardía en San Borja (1100-1470 d.C.) la caracterizamos como aquella construida en adobón (barro apisonado), con muros a base de bloques imbricados por adosamientos consecutivos solucionados en suave talud al exterior; su elevación fue lograda mediante la técnica de rellenar compartimientos interiores traslapados en verticalidad, teniendo muros medianeros internos que buzan de norte a sur y de este a oeste, sirviendo de contención a tales rellenos. Esta arquitectura externa se superpone a la más antigua del Horizonte Medio en planta y elevación rectilineales. La más visible al exterior, es masiva y técnicamente repetitiva en el monumento. Sus perfiles externos sur, este y oeste, así como un remetido frente norte muy destruido, muestran características típicas descritas. 
Recurrentemente, entre cuatro a seis muros externos adosados consecutivamente en suave talud, encierran, cercan y delimitan a la unidad arquitectónica interna con verticalidad de 7 metros de altura conservada en el ángulo sur-oeste. Los muros de bloques imbricados es morfología arquitectónica intermedio tardía y se correlaciona con arquitecturas arqueológicas de similar tipificación en Sullcovilca (Chorrillos), Mateo Salado pre-Tawantinsuyu (Breña-Pueblo Libre), Tres Palos (Pueblo Libre-San Miguel), Mangomarca (San Juan de Lurigancho), etc., lo cual significa coexistencia con otras markas paralelas asentadas en distintos rumbos del valle, compartiendo técnicas constructivas similares, como lo hemos explicado líneas antes.

La organización autóctona urbano-rural y arquitectónica alcanzada por los sitios de la época Lima II fue la "Marka" (territorio autónomo). En la marka se conocían los caminos hacia los sitios vecinos, como a aquellos asientos de mayor lejanía, entre los que mantenían relaciones diversas: se manejan las obras hidráulicas; comparten la dicotomía bilateral como base de la simetría socioeconómica, también las tendencias simbólicas y se pontifica el hermetismo de los lugares sagrados.

La época Intermedio Tardía (1000-1470 d.C.) enmarca una vida relativamente pacífica en la costa central, caracterizada por trabajo agrícola y pesquero, el ceremonialismo y las conexiones sociales recíprocas entre los asientos de próxima vecindad. Sus relaciones fueron establecidas en base a modelos colectivos de dependencias recíprocas y lealtades.

En cuanto a las relaciones de la nación menor Lima II con Pachacamac fueron establecidas en torno a la ideología religiosa del ídolo Ichimay, cuyo culto -desde fines del Horizonte Medio- habían adoptado las gentes del valle de Lima. Cerámica arqueológica Ichimay se encuentra en los diferentes sitios del valle de Lima, lo mismo que en San Borja, probando las conexiones e influencias ejercidas desde Lurín hacia Lima. Algo más: las prospecciones y estudios en el valle de Lima permiten identificar una fuerte ocupación Ichimay en el valle bajo medio de Lima (desde Armatambo en Chorrillos hasta Ate-Vitarte); en esta última zona encontramos 5 pirámides con rampa-eje frontal emplazadas delante del sitio de Huaquerones (ver plano isométrico), construidas con adobes y de tipología similar a las grandes pirámides con rampa-eje frontal originarias en el gran centro ceremonial de Pachacamac.

Necesitamos citar aquí los datos consignados por Cristóbal de Albornoz (1582) para confirmar documentalmente que los valles de Lurín y Lima formaban el núcleo del culto al ídolo Ichimay de Lurín. Dice Albornoz: "Rímac, guaca de los indios de Lima que se decían Ichimas, donde está la Ciudad de los Reyes, era una piedra redonda. Que está en un llano donde tiene la guerta Gerónimo de Silva”. La situación religiosa anotada por Albornoz identifica a la ciudad cultista de Pachacamac en su importancia regional orientando la vida ceremonial y cultista comarcanos, incluyendo Limamarka-Limatambo.

Las características ecosistémicas y geográficas básicas del valle de Lima, se interrelacionan para modelar los procesos interactivos del hombre sobre la naturaleza. Cerros, arenales y el mar constriñen al valle. Entonces, los pobladores y agricultores vivían cerca a las "lomas" y humedales; complementan temporalmente relictos de cacería ("lomas" de Amancaes y "lomas" de Atocongo) y construyen sus poblados y/o estancias en las colinas o laderas encumbradas, mientras que plantan sus centros ceremoniales y palacios en las llanuras nombradas donde ahora encontramos sus vestigios. Época de paz, coexistencia pacífica, de relaciones contractuales y de gran interacción social. La tierra disponible alcanzaba para satisfacer las necesidades de las markas y ninguna se levantó con intenciones de convertirse en jerarquía despótica hasta 1470 d.n.e. (impacto político del Tawantinsuyu). Las tumbas, los entierros y pozos sepulcrales, revelan las técnicas disponibles y el bagaje de sus creencias. Los textiles como documentos gráficos, maravilla de técnicas, iconografía y arte, revelan mentalidad abierta a la interpretación de la realidad. Se trata de una cultura compleja lograda viviente que super- 
vivirá a pesar de la colonia y que junto con las toponimias descubren las raíces telúricas ancestrales, constituyendo sus aspectos vivos más refulgentes.

El hombre de estos siglos se preocupó en el manejo del agua en el valle que lo distribuye por medio de canales y acequias hacia reservorios, de los que luego se vierte para el riego de las chacras. Los grandes canales de Maranga y Guadca así como los de La Legua, Magdalena y Surco, señalan disponibilidad permanente de técnica hidráulica y práctica de política agrológica en el valle.

En medio del paisaje rural crecían varios de los asentamientos sociales citados líneas antes; el clima templado; amenaza de temblores y falta de madera determinaron los materiales de construcción: muros de adobón grueso construidos en barro, pirámides edificadas por la técnica de adosamientos consecutivos o casas a base de simple barro amasado con techos de palo, cañas, ramajes o esteras de totora, proliferaban en el valle. La arquitectura Intermedio tardía yergue sus perfiles en suave talud o imagen escalonada, remanente similar de la tradición precedente en las grandes ciudades de Cajamarquilla (valle de Lima) y Pachacamac (valle de Lurín).

La extensión territorial Limamarka era en verdad corta. No alcanzaba a Maranga Intermedio Tardío (Pueblo Libre-San Miguel), Sullcovilca (Chorrillos), Carabayllo (Chillón), ni Latinmarka (Ate Vitarte), las que eran otras markas con sus propias autoridades, pero todas cobijadas bajo la advocación cultista de Ichimay (Pachacamac, Foto 10).

\section{El Tawantinsuyu en el Valle de Lima}

La expansión Tawantinsuyu a los cuatro rumbos andinos ocurre después de la victoria del Cusco sobre los Chanka. En plena expansión del Tawantinsuyu arriba al valle de Lima entre 1460 á 1470, tiempo que se infiere a partir de los datos arqueológicos y etnohistóricos. En el Cusco gobernaba el Inca Pachacuti, siendo su hijo el General Tupa Yupanqui quien ejecuta las expansiones hacia la Sierra Central, penetra en la región Cañari (actual Ecuador) y retorna dominando la costa norte (Chimú) y central del actual Perú (Limamarka, Sullcowillca, Pachacamac, etc.).

El directo conquistador de Lima es Tupa Yupanqui, al mismo tiempo que se anexa las otras markas de los valles comarcanos; realizada tal conquista, se emprendió la política de cusqueñización como era práctica frecuente del Imperio en regiones o valles incorporados a su dominio.

En San Borja Norte, las excavaciones arqueológicas han permitido encontrar cerámica Tawantinsuyu y posible arquitectura que correspondería a este período tardío. En el ángulo noreste del monumento se eleva la esquina formada por gruesos muros de adobón; su verticalidad a plomo y construcción rectilineal evidencia morfología diferente con relación a la construcción de muros en suave talud y terminales escalonados pre-Tawantinsuyu; esa esquina está en análisis referente a la posible remodelación y ocupación Tawantinsuyu del monumento.

El monumento de San Borja, como arquitectura local perteneciente a la marka "Lima", entra a formar parte del Tawantinsuyu y su gente sufre los trastornos propios de la nueva situación política. Se impone la institución política y administrativa denominada "Tambo" para funcionar como organismo de control social y político en el orden local y del valle. La gente Lima se encuentra a disposición de las órdenes que imparte el Cusco. La población de Lima, antaño subsidiaria religiosamente de la deidad Ichimay de Pachacamac, pasa ahora a la advocación de la Iglesia Solar cusqueña. Empero la importancia de Ichimay como oráculo regional se convierte en un modelo para su implantación Tawantinsuyu en Lima (oráculo de Limatambo). Toda la información etnohistórica señala la ubicación de tal oráculo en Limatambo. El nombre del primer aeropuerto de la capital del Perú se ubicaba 


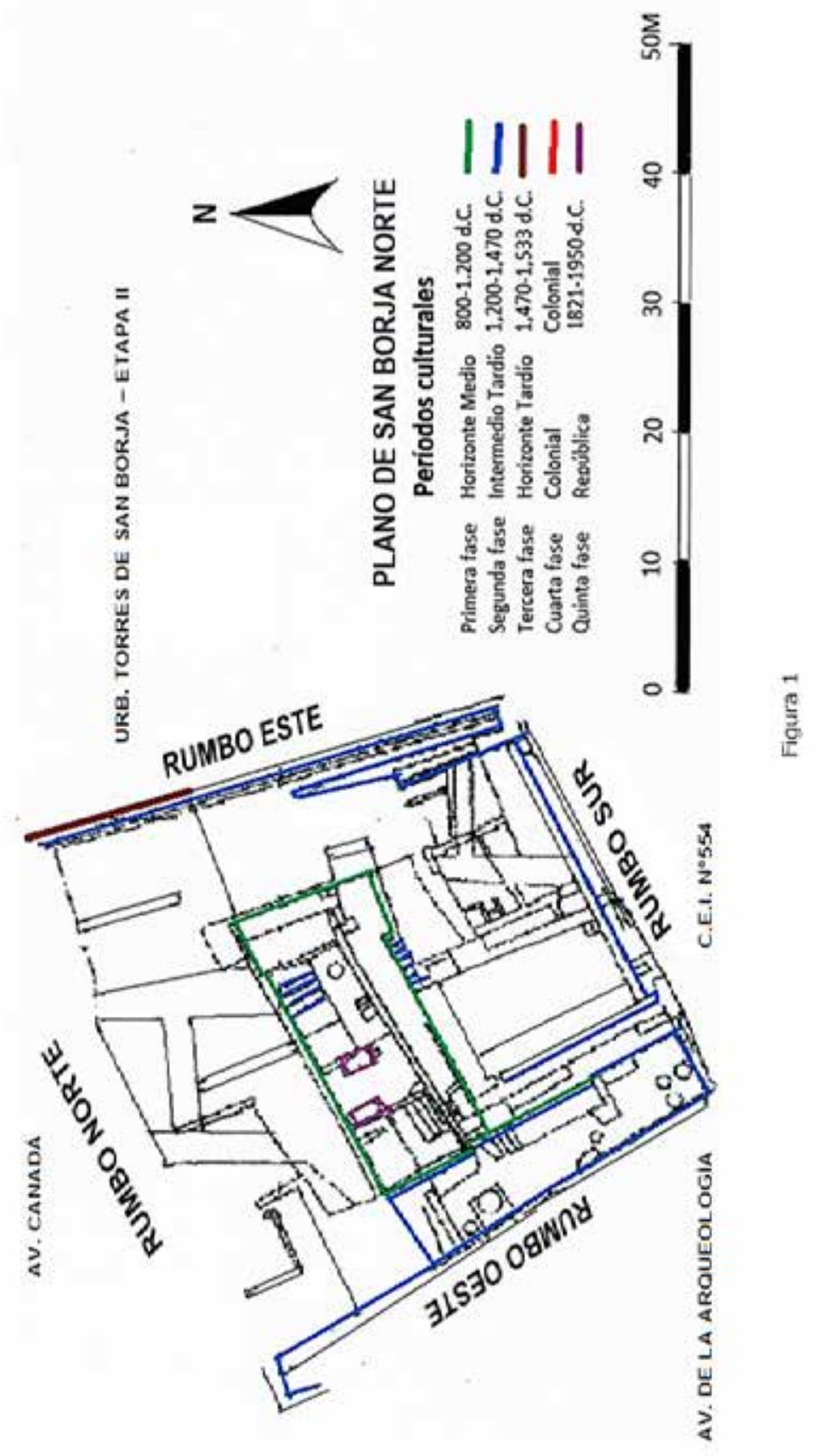




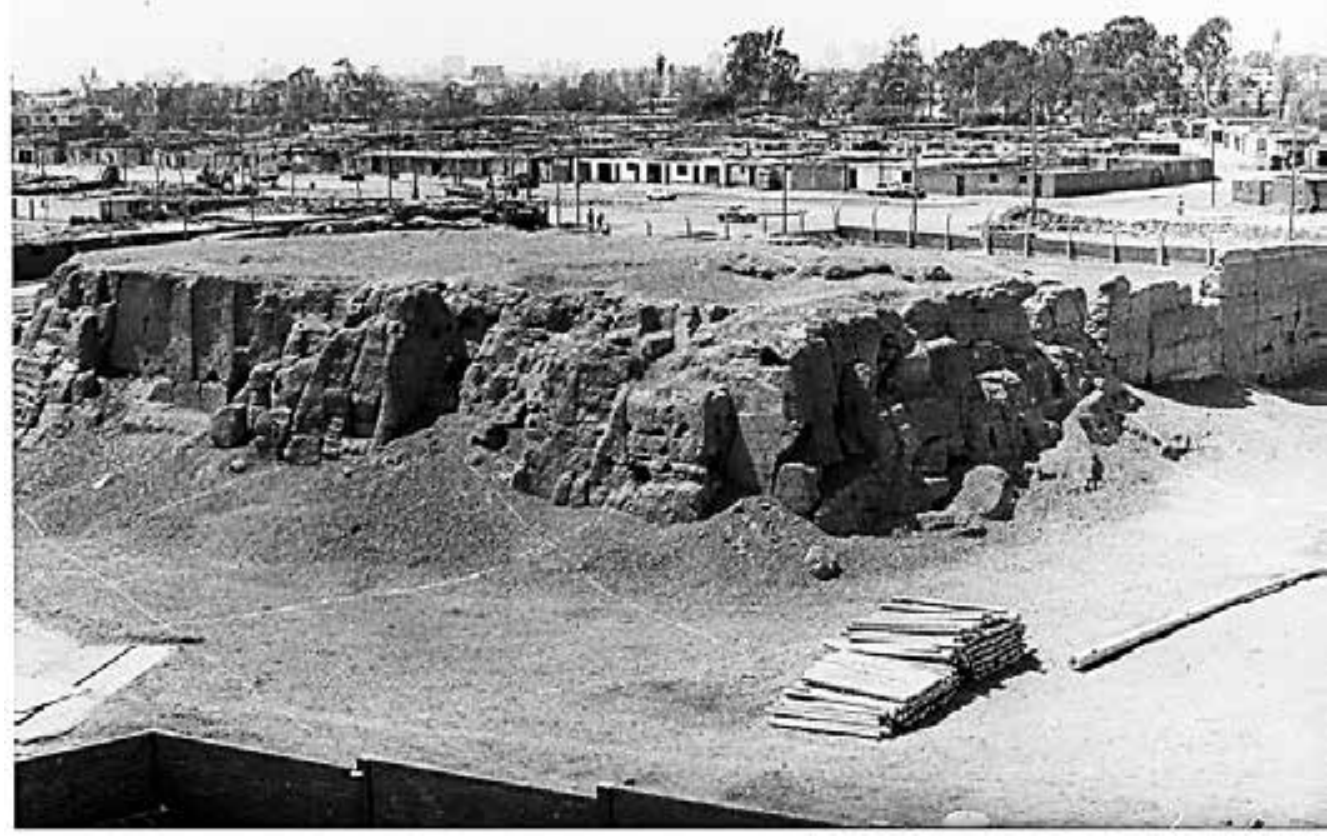

Foto 1: El monumento San Borja Norte destacando su planta y elevación en cuadro antes de comenzar los trabajos. El edificio se muestra limpio y despejado de los escombros y basura que lo cubría con anterioridad.

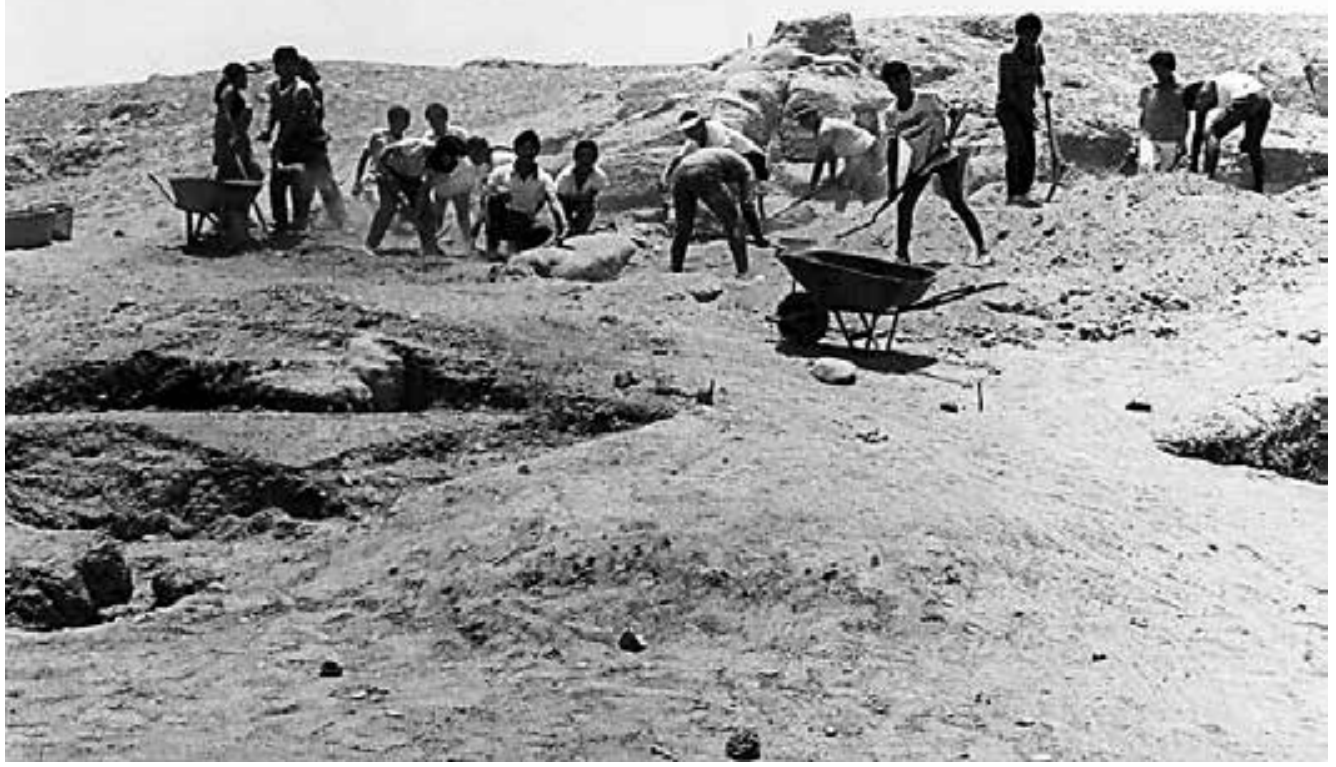

Foto 2: Inicio de los trabajos de excavación arqueológica (1989); al comienzo contamos con alumnos sanmarquinos de Arqueología por unos 30 días. 


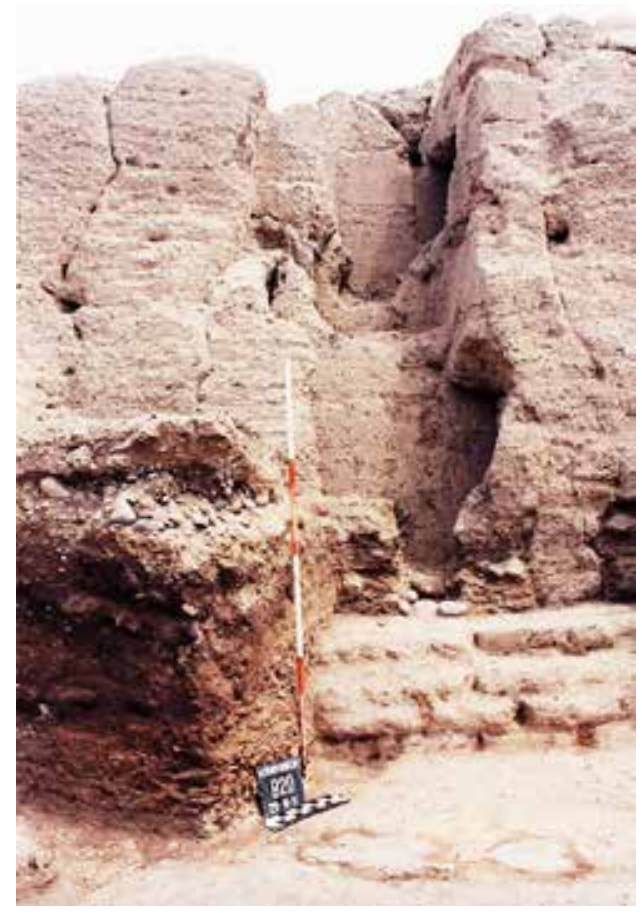

Foto 3: Cuadrícula B20. La ilustración muestra el faltante del frente oeste en orientación vertical. Aquí notamos del interior al exterior cuatro planos nítidos: Horizonte Medio el más interior; Intermedio Tardío el muro medio de bloques construidos por adosamientos consecutivos; el zócalo de adobes corresponde al Horizonte Tardío; el piso inferior externo es base de todo el edificio arqueológico.

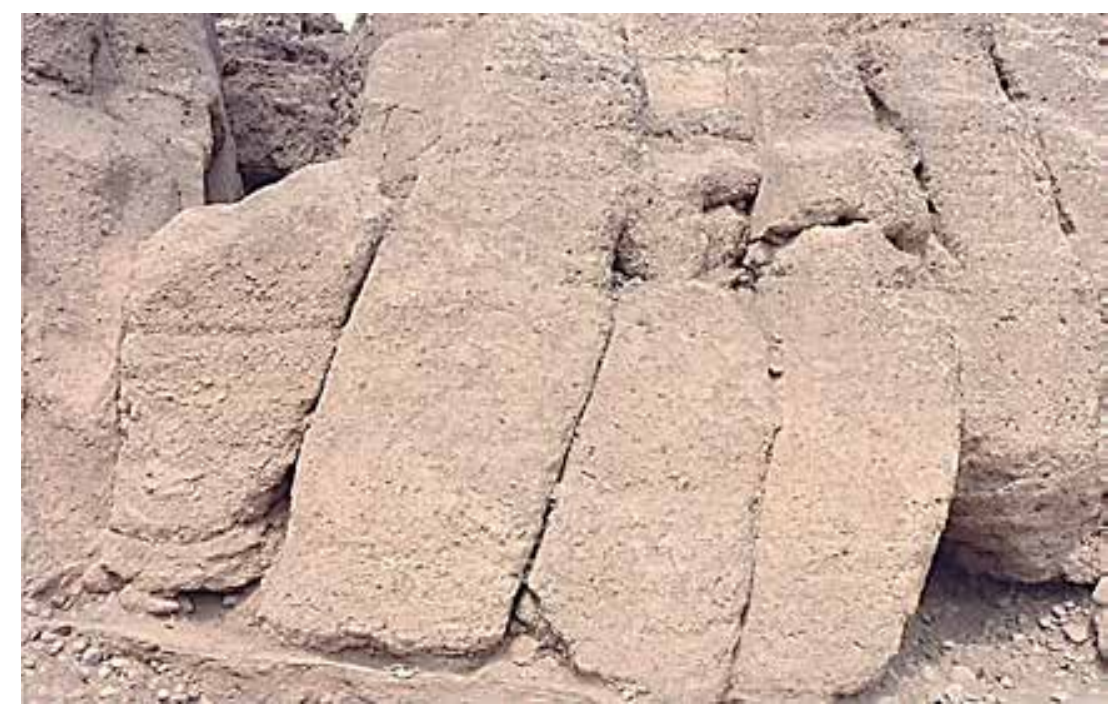

Foto 4: Muro externo oeste Intermedio Tardío con bloques asentados por adosamientos consecutivos que se imbrican unos a otros, tanto en lo vertical como en horizontalidad. Estos bloques se conservan en tres lados del monumento. 


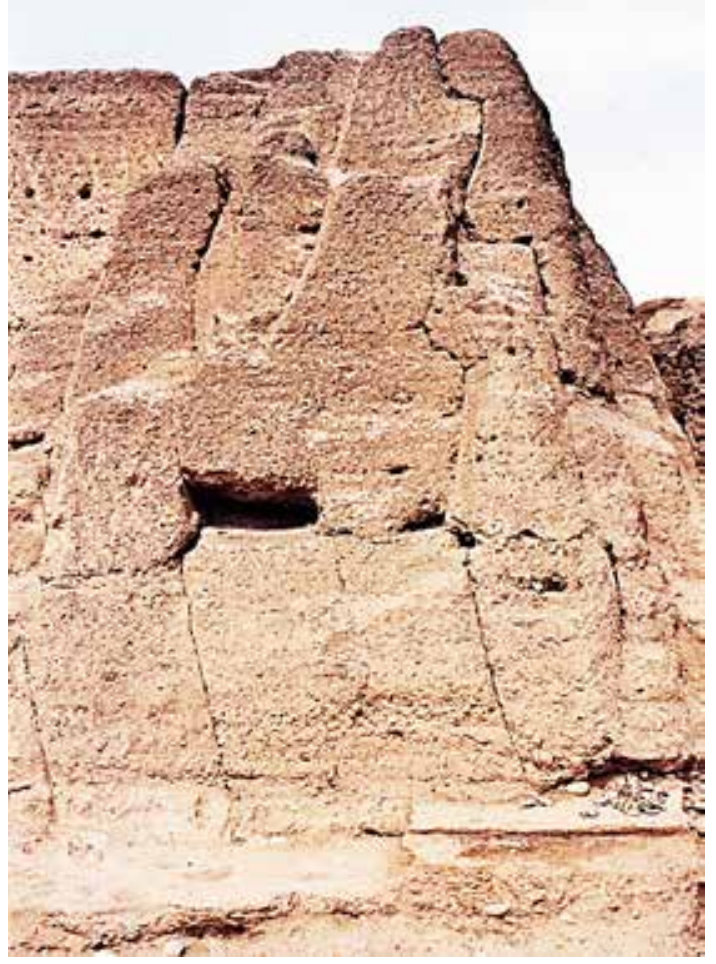

Foto 5: Muro de la esquina suroeste externa destacando las trabazones por adosamientos consecutivos explicados.

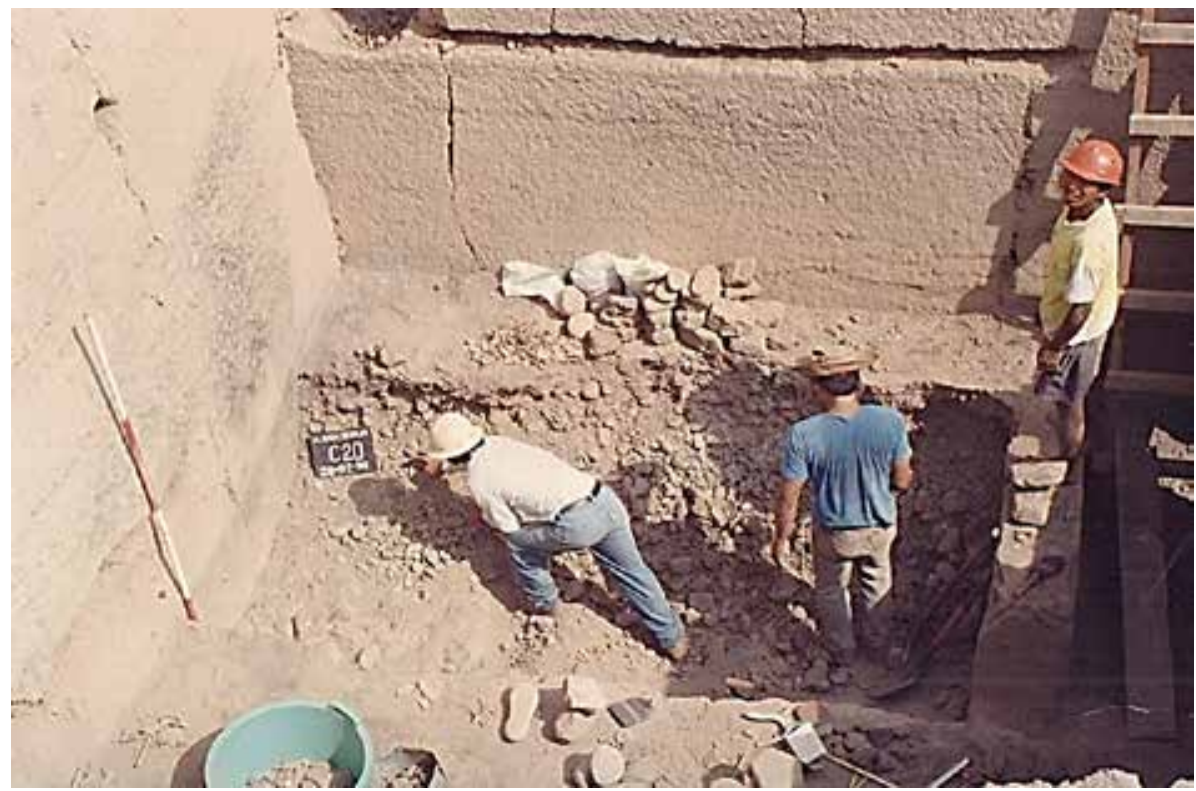

Foto 6: Cuadrícula C20 en plena excavación por decapado; el nivel de capa es de $4.00 \mathrm{~m}$. de profundidad y el estrato correspondiente es Intermedio Tardío. 


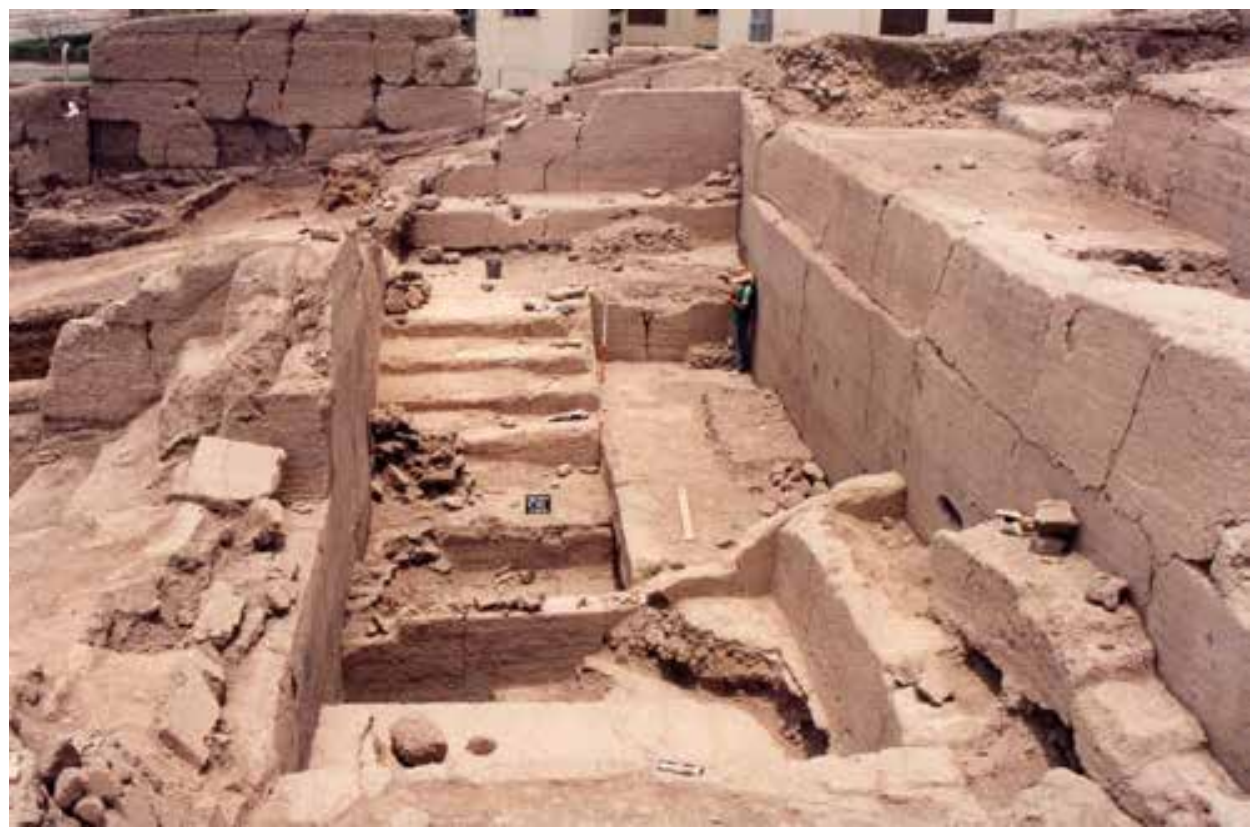

Foto 7: Cuadrícula C30 del interior céntrico del palacio, el que muestra su perspectiva constreñida por muros laterales, banquetas de corto alcance, escalera de 7 peldaños, pequeñas plataformas escalonadas, etc., indicadores de arquitectura compleja de mucha significación.

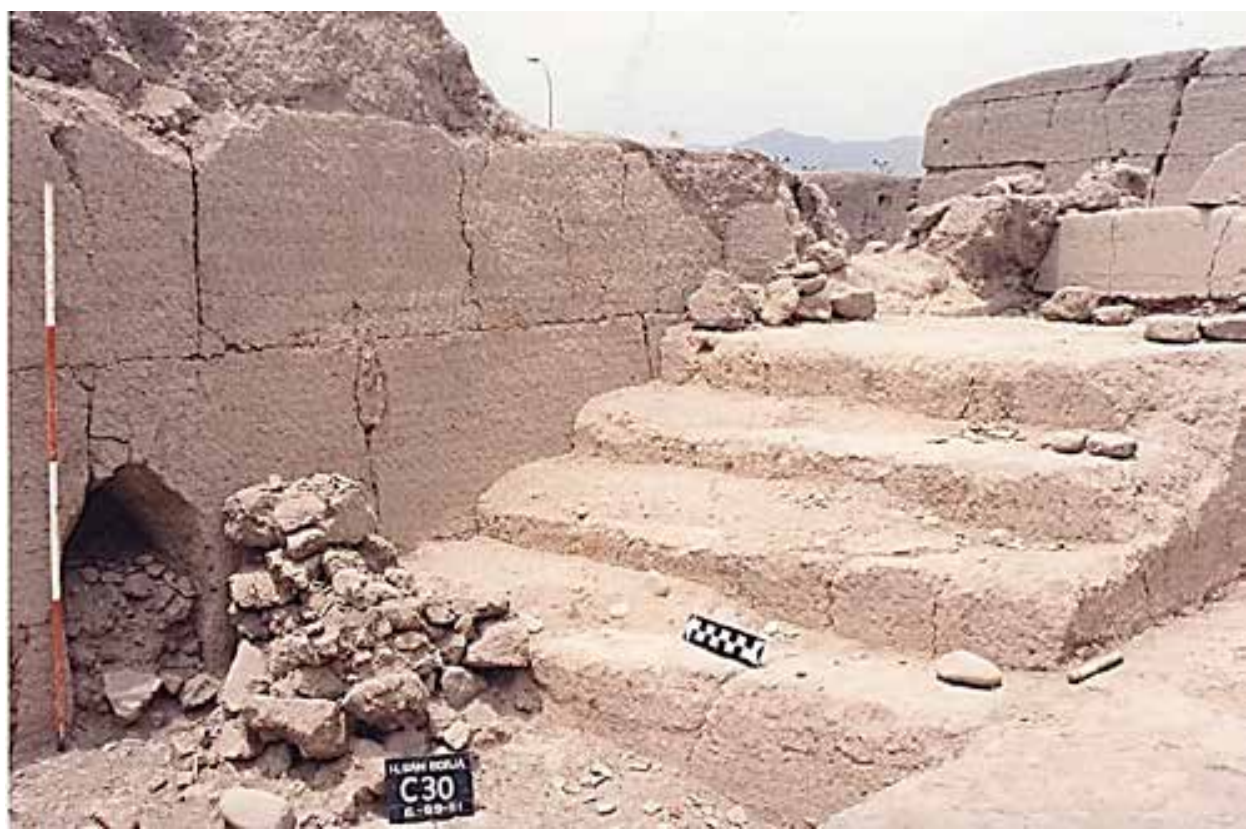

Foto 8: Cuadrícula C30 del interior céntrico norte donde mostramos su escalera en pleno proceso de descubrimiento; se ven todavía los terrones que lo enterraban y se despeja una rotura apuntada en el paramento interior lateral derecho. 


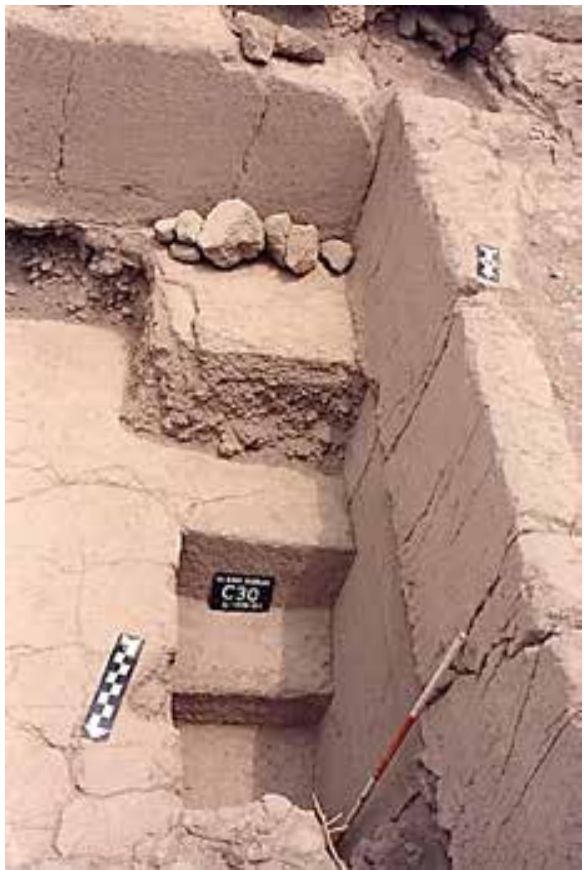

Foto 9: Cuadrícula C30 del interior céntrico sur; se ilustra el testigo del relleno del piso inferior en cuyo lado al muro lateral desciende una escalera al piso C20 inferior. Notar la finura de los pisos y tábicas de la escalera.

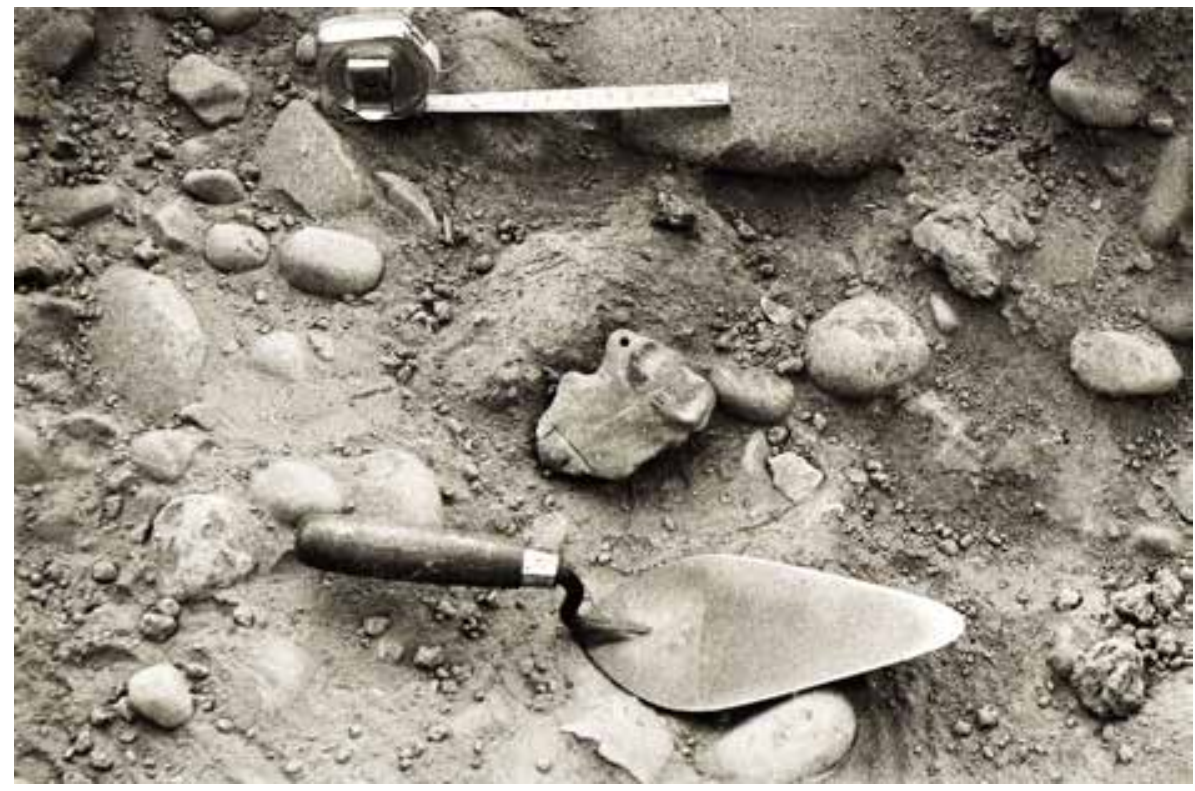

Foto 10: Excavaciones arqueológicas en la cuadrícula B20, parte alta, donde se descubre una figura de cerámica, sexo femenino; el estilo es Ichimay, sus brazos y manos protegen sus pechos y abajo del abdomen está muy demarcado el pubis y la vagina. La cabeza desprendida no fue encontrada. 
en lo que hoy es Corpac (fundo Santiago de Limatambo Sur en la Colonia), urbanización residencial del distrito de San Borja.

Bien, ahora no quedan monumentos visibles allí, pero sí en los alrededores del Complejo Habitacional Limatambo, donde hay dos montículos arqueológicos para próximas excavaciones y detrás del Estadio Municipal de Surquillo ubicamos el montículo conocido como "Las Mercedes", construido en adobón, actualmente bajo el cuidado del Ministerio de Cultura.

El sitio arqueológico de Limatambo empezó a ser destruido desde la colonia, debido a las excavaciones (huaqueos), que obligaban a hacer los españoles a la gente oriunda; en realidad se trataba de verdaderas demoliciones, desplomes y minados para buscar tesoros durante los siglos XVI, XVII y XVIII. Ephraim George Squier el proto-arqueólogo norteamericano y uno de los viajeros importantes de la segunda mitad del siglo XIX, escribió hacia 1865: "Los [monumentos] de Limatambo también estaban en vías de demolición, a manos de los ladrilleros...” Squier, 1974, p. 46). El viajero alemán Ernst W. Middendorf, 1984, T. II, escribió: "El dios del valle de Lima era el Rímac, cuyo templo vemos hoy día en la cercanía de la hacienda de los dominicos, que antiguamente se llamaba Rimactampu, y que ahora, debido a la pronunciación equívoca se conoce como Limatambo. En esta huaca comenzaba la antigua ciudad y se extendía hasta Maranga, como lo comprueban las ruinas que allí existen" (ibidem, p. 67).

En la primera mitad del siglo XX el Dr. Julio C. Tello siempre estuvo en franca lucha con los adoberos (especialmente italianos) que explotaban los montículos arqueológicos, cuya tierra y terrones eran convertidos en barro para labrar ladrillos, nuevo material de construcción de fuerte demanda por los constructores citadinos (Tello, 1999, p. 31 y ss.). Tello señala el término Lima para denominar al valle y relaciona al conjunto de las markas pre-españolas del valle de Lima como las sedes del desarrollo cultural independiente pero conectados en base a sus organizaciones sociales, ideología religiosa en torno a Ichimay de Pachacamac, cooperación colectiva para el trabajo agrícola y reciprocidades duales de comportamientos simétricos intramarkas e intermarkas, sobre todo en la esfera de relaciones significativas simbólicas de extensión multirregional.

De la prestancia arquitectónica originaria de Limatambo, sólo se han conservado el Palacio de San Borja Norte y dos montículos arqueológicos dentro del Complejo Deportivo Municipal del distrito. Tales montículos están muy recortados con respecto a sus dimensiones y formas originales, pero la arquitectura en adobón a la vista demuestra las evidencias de su antigua grandeza.

\section{La INFORMación ETNOHISTÓRICA, INVASIÓn EsPañola y Despoblación ORIGINARIA}

Hernando Pizarro que cruzó el valle de Lima a comienzos de 1533 se detuvo en Sullcovilca (Chorrillos). Miguel de Estete, cronista que lo acompañaba, narra que tembló la tierra cuando se encontraban en este pueblo al pie de la falda noreste del Morro Solar; desgraciadamente no aportan mayores datos acerca del gran sitio.

Los datos etnohistóricos tempranos para Lima son muy escuetos, parcos y restringidos. Alonso Enrriquez de Guzmán que conoció la costa del país en 1534, observa que "no tienen casas sino de setos en cañas como corrales de gallina y ansí sucias y desbaratadas". Agustín de Zárate dice en 1543 que "los indios de la costa no viven en casas, sino debajo de los árboles o de ramadas".

Evidentemente estos españoles trasmiten una visión restringida al ámbito rural de patrón disperso y por lo tanto muy parcial, debido a que la supervivencia arquitectónica arqueológica muestra distinto panorama. 
Cieza de León se encontraba viajando por el país a partir de 1548 y este autor anota que "los indios de los llanos y arenales no hacen las casas cubiertas como las de la serranía, sino terrados galanos o grandes casas de adobes con sus estanques y para guarecerse del sol ponían unas esteras en lo alto". Los datos de Cieza de León como se puede apreciar, están más cerca de la realidad comprobada por la arqueología en nuestros días.

Pedro de Alconchel (1536) afirmaba que "había muchos árboles de frutales y bosques dellos". En la segunda mitad del siglo XVI el mismo Alconchel menciona que "los indios están reducidos a un rincón”. No es posible precisar a qué gente andina se refiere; parecería ser esta una opinión sobre el estalaje de la población andina en general.

El tumbesino don Pedro Challanay residente en el valle de Lima, asegura que "cuando entró el Marques hera todo de frutales, de guavos y guayabas e lúcumos y otras frutas y ansí mismo de camotales e donde cojían sus comidas".

Fray Gaspar de Carbajal observa en 1560 que Lima tenía "montes de arboledas e así lo era el sitio de esta ciudad e se ivan los españoles dos leguas sin que les diese el sol e todos estos árboles eran frutales e agora ve que no hay ninguno".

Fray Antonio de Calancha (1630), confirma que "cerca de Maranga estaba el pueblo de Lima que tenía aproximadamente media legua [dos kilómetros y medio de extensión en forma de patrón concentrado] y se hallaba junto a la Huaca o Templo del dios Rímac, oráculo de la región". "Desde Limatambo a Maranga había una serie de enterramientos y casas o palacios, uno del rey Inca (Mateo Salado), otro del cacique del pueblo y los demás de caciques ricos. Junto al río Rímac, a la banda del sur, había un lugarejo o tambo en el mismo lugar que hoy ocupa la plaza y casas reales que pertenecía, como tierras colindantes, al cacique de Lima y que fue escogido por Pizarro para asiento de la ciudad"... "por hallarlo ya provehido de agua, leña y otras cosas necesarias a una república y lo otro porque conjeturaban que sería el más sano".

La provisión de agua y su distribución por canales arqueológicos a través del valle, es así uno de los motivos determinantes para la elección del sitio de la ciudad española. Las acequias arqueológicas cumplen así un papel decisivo a las necesidades de los españoles.

Los datos consignados por el padre Bernabé Cobo (1610-1630) ilustran sobre tres reducciones: Surco al sur-oeste del valle; Maranga en el valle bajo central y Carabayllo en la margen izquierda del río Chillón. Surco era la reducción más grande del valle. Cobo, para comienzos del siglo XVII (1610-1630) anota: "las casas del curaca con las paredes pintadas de varias figuras, una muy suntuosa huaca o templo y otros muchos edificios que todavía están en pie sin faltarles más que la cubierta". Los demás pueblos dice Cobo "eran lugarejos de corta vecindad", pues los ve diseminados por el valle y no tan concentrados como aquellos, porque Cobo es un magnífico cronista y erudito, pero tardío (la primera mitad del siglo XVII).

Al fundarse la Ciudad de los Reyes (18-01-1535) el Curaca principal de Limamarka se llamaba Taulichusco desde el tiempo de Huayna Capac; debido a que "Taulichusko era viejo" (1535), su hijo Guachinamo ejercía el gobierno sólo reservándose para aquel su prestigio de Principal. Guachinamo murió y le sucedió don Gonzalo, quien fue retirado a vivir en extramuros, ocupando chacras ubicadas donde hoy es la iglesia de San Sebastián. Tiempo después también es erradicado del lugar y durante el gobierno del Virrey Marqués de Cañete lo encontramos viviendo reducido en el pueblo nuevo de La Magdalena; en 1555-1559 don Gonzalo hace noticia al elevar sucesivamente dos probanzas a la Real Audiencia de Lima como testimonios de servicios a la corona y reclamar sus derechos sobre las tierras 
del valle que ancestralmente pertenecían a su familia. Don Gonzalo dona las tierras necesarias para el templo y convento de los franciscanos en Magdalena. No se sabe cómo ni dónde muere; tampoco se sabe el lugar de su sepulcro.

El pueblo nuevo de La Magdalena (Mozoqllaqta) sustituyó a Limamarka como residencia del curaca andino tardío para adoctrinamiento, bajo la advocación de la orden franciscana y alejarlo de sus asientos originales, así como de sus prácticas autóctonas de vida.

\section{InVASIÓN EsPañola y Despoblación del VaLLE dE Lima}

Entre 1524, 1528 y definitivamente en 1532 el Tawantinsuyu fue invadido por los españoles, quienes llegaron a nuestro país por la vía marítima septentrional del Chinchaysuyu.

Es verdad que existen toda clase de dificultades para cuantificar a la población andina total, porque los quipu fueron destruidos, los españoles no levantaron censos inmediatos sobre densidades urbanas, ni rurales, etc., pero los estudios arqueológicos contemporáneos con hallazgos de ocupaciones humanas en todos los pisos ecológicos andinos -desde la orilla del mar hasta los cinco mil metros de altura- incluida la foresta amazónica, otorgan datos que permiten nuevas cuantificaciones más cercanas a la realidad.

Los numerosos sitios arqueológicos - muchos de ellos destruidos- pero físicamente evidentes por todo el país, ameritan nuevas cuantificaciones en término de población. Pero también, hoy en día consideramos que las mayores densidades demográficas vivían en el campo, con patrón espacial disperso, pero con gran sentido de pertenencia al ayllu, la mitad, la marka, etc., los que no perdían sentido al ser poblanos o citadinos. Es decir, el campo y los pueblos y ciudades del Tawantinsuyu eran poblacionalmente indistinguibles; gente poblana o citadina siguió cumpliendo roles campestres según su contexto social. Estos son difíciles de cuantificar, pero para el siglo XVI todo el Tawantinsuyu rural o citadino rebosa de gente originaria por todas partes.

Como se sabe, el Pacificador La Gasca (estuvo en el Perú entre 1546 y enero de 1550) dispuso el levantamiento de un censo que debió realizarse entre 1548 á 1553. Tal censo no abarcó la Selva y tampoco “comprendió las provincias de Chile, Tucumán y otras: alcanzó la cifra de 8'285,000 habitantes”. La cifra ha sido repetida por gran número de estudiosos, sin embargo, no es posible saber los territorios específicos censados, ni tampoco cómo se obtuvieron las cifras parciales y/o la cifra total. Tampoco se tuvo en cuenta a las poblaciones muertas entre 1532-1548.

Cristóbal de Molina el almagrista, también signado "el chileno" (1553), relata: "y este valle de esta ciudad había y en Pachacamac cinco leguas de aquí que todo era una cosa, más de 25,000 indios, y está casi yerma que apenas hay dos mil por la gran destrucción y tan continua, como ha tenido de tantos ejércitos que en ella se han formado en tanto daño y perjuicio de los naturales, los cuales perecieron por una regla general que se han usado en estos reinos; y aún creo yo que en la mayor parte de las Indias, que los indios más cercanos con los españoles y que mejor servían, aquellos son más robados, vejados muertos y fatigados...".

Asumiendo que la tasa de mortalidad causada por enfermedades europeas entre 1520 á 1570, se puede determinar por el aumento entre las distintas epidemias en el Perú, para 1520 tendríamos entre 8 á 9 millones de pobladores (determinados con cautela). Las epidemias de sarampión, viruela, difteria y escarlatina diezmaron poblaciones en el siglo XVI en medio de otros factores de descenso poblacional (José Toribio Polo, 1913). 
La virulenta epidemia de difteria (1589-1591) afectó Lima y sus contornos rurales, de la cual no tenemos cuantificación ni número de fallecidos. Pero en 1613 la población de Lima era únicamente de 268 personas, siendo el porcentaje de la población oriunda total en Lima de 13,8\% debido a los migrantes (de todas partes de la colonia migraba a Lima), por los cuales Lima tenía pobladores y mano de obra (Noble David Cook, 1981, pp. 207 y ss.).

Cook (1981): estudia y revisa los datos y criterios que se han seguido para determinar los volúmenes poblacionales para los tiempos arqueológicos:

1. El enfoque ecológico: analiza las condiciones y potencial de recursos del territorio para proporcionar alimentación a la población; por este criterio considera un máximo de 13 millones de habitantes, de los cuales, unos 6 millones vivirían en la costa.

2. El enfoque arqueológico: en este campo los estudios están en sus comienzos, por tanto los datos son todavía incipientes. Parte del conocido concepto de que en los centros poblados, las gentes eran fluctuantes, siendo hipotética su cuantificación en atención a lo construido. Ejemplo: Chan Chan 25000 habitantes. Pachacamac, 500 á 1000 gentes permanentes y una población reciclante de 2000 personas.

3. El enfoque de despoblación: a partir de datos cronísticos, realiza inferencias utilizando ejemplos referenciales conocidos. Para tal efecto cita a Rowe, quien estudiando los modos de despoblación de los valles Rímac y Chincha y aquellos de la sierra (Yauyos, Huancas y Soras), concluye que la población total pudo haber sido de unos 6 millones de habitantes en el conjunto de tales territorios. No dice nada de los otros territorios con muchas poblaciones y que él omite o no considera por falta de datos.

En la probanza de Lima (1555-1559) don Gonzalo, Curaca de Lima, afirma que cuando llegaron los españoles al valle sus pobladores eran "en cantidad de 4000" y que "al presente habrán quedado hasta doscientos y no más": el testimonio de los curacas don Santiago Chimanaza y don Pedro Chalanay confirman la cifra de cuatro mil habitantes que conformaban la Marka de Taulichusco.

Procesando los datos del valle de Lima encontramos que en los dos primeros decenios, a partir del arribo de los españoles, presentan la caída más brusca, sobre todo en los quinquenios que van de 1535 á 1545 , con $34 \%$ de disminución poblacional.

Es realidad evidente durante el siglo XVI que la población autóctona del Tawantinsuyu disminuyó de manera significativa, igual que en los otros territorios americanos. Hacia 1570 la población andina quedó reducida a cerca de 1'300,000 habitantes y quizá a unos 2'000,000 en ámbito sudamericano hacia 1580-1600, es decir a menos del 15\% de la cantidad que había sido sólo medio siglo antes. La despoblación de la costa alcanzó ribetes dramáticos y para 1560 no llega ni al 5\% de la que habría sido anteriormente; para estos años la costa central alberga sólo al 4.5\% de la población que había tenido en 1520 y la costa sur incluso reducida a un porcentaje menor.

A estas alturas del estudio es importante que sigamos la historia de las tierras donde hoy en día encontramos al distrito de San Borja, desde sus comienzos hispanos, cuyo impacto sobre las poblaciones oriundas del valle constituyó verdaderas catástrofes de variados tipos. 


\section{La Historia de San Borja Hasta el Siglo XviII}

Las tierras del hoy distrito de San Borja tienen una historia paralela a la ciudad de Lima, pues fueron entregadas por Francisco Pizarro, personalmente, a su secretario Antonio Picado a comienzos de Enero de 1535, quien al mismo tiempo ya era encomendero de Jauja y luego Regidor del Cabildo de la ciudad de Los Reyes, el cual como puede notarse gozaba de la confianza absoluta del Gobernador como asesor y consejero. Picado tomó posesión de las tierras asignadas: suelo, sembríos naturales y la gente autóctona en condición de esclavitud. Escribe Fernando Flores-Zúñiga (2009)... “el sensual Antonio Picado hubo de tomar para sí el sector más vivo y activo del valle rimense; una zona que bebía copiosamente de dos de los tres grandes canales que vivificaban dicha vega: el de Surco y del de Huatica, cuyo nombre se debía precisamente ala urbe de tapias y adobes que serviría de germen predial a la futura hacienda San Borja" (ibídem, p. 278). Así, con Antonio Picado las tierras de Limatambo se convierten en encomienda temprana sin límites en el centro del valle de Lima, únicamente constreñidas por otras propiedades (encomiendas) de otros españoles que Pizarro iba poco a poco repartiendo entre 1535 á 1941, año este último en que fue muerto por los conjurados del bando almagrista acaudillados por Diego de Almagro "El Mozo". Después del deceso de Pizarro, los almagristas decapitaron a Picado el 29 de Junio de 1541.

De esta fecha para adelante heredó las tierras su mujer Ana Suárez, quien en segundas nupcias se casó con el español Sebastián Sánchez de Merlo, Encomendero de Huarochirí, por entonces "Secretario de la gobernación de estos Reynos"; a la muerte de Ana Suárez quedó como heredero general este español, el que concertó en casar a su hermana doña Quiteria Sánchez de Merlo con el español Francisco Ortíz de Arbildo (1558), cabildante y vecino de Lima (cita de Lohmann Villena, 1983, II: pp. 220 y 282; por Fernando Flores-Zúñiga, 2009, p. 280).

Citando el legajo signado como Título de la Hacienda [...] llamada San Francisco de Borja, Años 1594-1697, Archivo General de la Nación, Títulos de Propiedad, leg. 14, c. 303: fs. 3 passim, Fernando Flores-Zúñiga publica los documentos de Archivo citados en su libro Haciendas y Pueblos de Lima-Historia del valle del Rímac, Valle de Sullco y Lati: Ate, La Molina, San Borja, Surco, Miraflores, Barranco y Chorrillos. Fondo Editorial del Congreso del Perú y Municipalidad Metropolitana de Lima, Lima T. II, 2009, 727 pp., el cual es fuente de primer orden para este estudio y otros que se harán a futuro, respecto a los tiempos de 1535 hacia adelante. La familia Sánchez de Merlo-Ortíz de Arbildo como encomenderos de las tierras de Limatambo (200 fanegadas) tenía como vecinos por el sur a los predios de Santiago de Limatambo y tierras de Surco, todas irrigadas por el acequión de Surco; hacia el oeste Flores-Zúñiga aporta la siguiente cita a pie de página: “Córdova y Urrutia [1839], 1992, I: 122. Dice el estadístico decimonónico que "[...] hasta el año de 1594 se conocía [...] un pueblo, situado a espaldas de Limatambo, y tomaba hasta Maranga [...]"; o sea, Guadka (Guatikamarka) que le daba nombre al valle extendido a sus pies" (ibídem, p. 280).

El estudio contrastado entre la documentación citada y las investigaciones arqueológicas permite revelar que hasta 1594 las tierras de la hoy San Borja todavía no tenía este nombre, sino que conservaba el antiguo pre-español de Limatambo. La familia de peninsulares citada poseyó por más de 30 años tales tierras, trabajándolas mediante agricultura de riego con las aguas del canal surcano, el que a la fecha discurre todavía a la vera del "pentagonito", distrito de San Borja.

Hacia la segunda mitad del siglo XVI la ciudad de Los Reyes ya era el centro administrativo de todo el imperio español en sudamérica. El 26 de Noviembre de 1569 llega al Perú el Virrey Francisco de Toledo y el 22 de Octubre de 1570 se instala en Lima el Tribunal de la Santa Inquisición con juris- 
dicción en todo el virreinato peruano. Entre 1589-1591 se presentó una virulenta epidemia de difteria muriendo mucha más gente andina que española.

Por desgracia los españoles no tuvieron interés en describir las poblaciones de las markas, ya que únicamente de manera muy general es noticia en los documentos de archivo algunos topónimos, grandes muros, ruinas de poblados, un gran "camino alto" llamado de Pachacamac, etc. Por eso es que los autores al tratar de reconstruir la realidad sociocultural o la ubicación de los asentamientos originarios en el valle de Lima, carecen de fuentes seguras y por eso se les ocurren adivinanzas acerca de las identificaciones de los lugares de las markas originarias, que ahora en esta publicación las ofrecemos con mucha aproximación líneas antes.

"El camino alto" era un gran camino arqueológico delimitado por altos muros de adobón paralelos, en cuyo centro estaba el piso muy bien construido; un buen tramo se encuentra en el interior del Parque de las Leyendas desde donde atravesaba el valle de Lima empezando en la zona arqueológica de Malanka/Maranga (al interior del Parque de las Leyendas), continúa con otro magnífico tramo conservado en el campus de la Universidad Católica, continuaba entre Limatambo y Chacarilla del Estanque, enrumbándose adelante a la quebrada de Atocongo para ingresar a Pachacamac por la puerta de la muralla norte, dirección de "José Gálvez" y la fábrica de Cementos Atocongo. Este gran camino sólo existe al presente en los dos tramos citados, estando totalmente destruido en las otras áreas.

En 1593 el hijo de Francisco Ortíz de Arbildo, don Gregorio Ortíz de Arbildo nacido en Los Reyes (1560) y cuya madre fue la española Quiteria Sánchez de Merlo (muerta en 1571), se casó en 1588 con doña Catalina Gil de Avis de Lagos. Fue regidor perpetuo de Lima en 1587 hasta su muerte acaecida el 15 de abril de 1597 (cita de Lohman Villena, 1974, II: [219] 220) por Fernando Flores-Zúñiga, op. cit., 278 y ss.). Este criollo introdujo la cría de ganado en Limatambo, convirtiéndose en el principal abastecedor de carnes al mercado abierto de Los Reyes, ciudad a la que también proveía de trigo, maíz y caña de azúcar que sembraba en el valle de Pachacamac, de igual sembraduras posibles en Limatambo. En noviembre de 1593 Gregorio Ortíz de Arbildo solicita ante el despacho virreinal ejercido por el primer Marqués de Cañete una visita de recomposición territorial en las tierras prediales de Limatambo, heredada de sus padres. La remensura y recomposición procedía por existir una Real Ordenanza, que el tercer Virrey del Perú don Andrés Hurtado de Mendoza (1556-1561) debía hacer cumplir en todo el virreynato, así como cobrar las tasas por derechos de propiedad a partir de estas nuevas recomposiciones de real autorización (Títulos de la Hacienda de el Valle de Surco llamada San Francisco de Borja, Años de 1594-1697, Títulos de Propiedad, leg. 14, c. 303: ffs. 1 v. y 2, Archivo General de la Nación) pub. Fernando Flores-Zúñiga, op. cit., p. 279.

Por esta Real Ordenanza se cumple la diligencia de medida y remensura en las tierras de Gregorio Ortíz de Arbildo; el protocolo publicado por Flores-Zúñiga (op. cit., p. 281) informa en sus inicios [apostilla: "medida"] estando en la chacra de Gregorio Ortíz de Arbildo que es en términos de la ciudad de los Reyes del Perú, entre el Camino Alto que va a Pachacamac, el día miércoles primero del mes de diciembre de 1593 años [...] se comenzó la medición con asistencia del medidor Pedro de Portillo, Alguacil Mayor" (traducción paleográfica nuestra). El análisis de este documento permite conocer que en la zona aparecen otros tenedores de tierras como los dominicos, los mercedarios, un portugués llamado Antonio Hernández dueño de una chacra de pacaes y, todavía la presencia de “...unos paredones antiguos que hacen como una calle o camino [...] pasando junto a una huaca..." (ibidem). Como puede apreciarse, los datos arqueológicos son muy escuetos, con los cuales no podemos hacer mayores inferencias de precisión ubicativa monumental. 
Los actuales testimonios arqueológicos están muy dispersos y alejados. Fernando Flores-Zúñiga solo acierta acerca del importante camino real que conducía a Pachacamac, "santuario universalmente consagrado en lo que concernía a la Costa Central peruana. Saltando los muros de dicho camino, se extendía los ámbitos dominicos de Santiago de Limatambo Sur y Norte...” (ibidem, p. 282). Al finalizar el siglo XVI irán apareciendo otros poseedores de chacras en las tierras de la futura San Borja, cuyo nombre aparece y se gesta a fines del siglo XVII y comienzos del siglo XVIII. En el siglo XVII se organizan las haciendas coloniales en todo el Virreynato Peruano con características relacionadas a cada región y situaciones político-sociales peninsulares. La gente andina sólo era considerada para el trabajo gratuito esclavizado.

El 20 de Abril de 1654 Juan de Sandoval y Guzmán vende una parte de su fundo por medio de escritura y concierto a don Antonio de Avellaneda y Zúñiga y Gregoria de Avis de Lagos su mujer, ante el escribano Real Pedro Lopes (sic) de Amalla (sic). Por tanto, las tierras que venían conociéndose como el fundo Sandoval con riego de veinte y dos fanegadas y media fue vendido de a pocos (por chacras); al correr los años una parte de las tierras de unas hermanas Camarena serían reagregadas a las que fueron propiedad de Sandoval y Guzmán y Arbildo y otros propietarios sucesores hasta la llegada de los jesuitas, tiempo en que las dimensiones de las tierras alcanzarían la extensión aproximada de 280 hectáreas (100 fanegadas y su agua de riego).

Juan de Sandoval y Guzmán y Arbildo también había vendido a don Francisco de Arano el 8 de Julio de 1653, morador de Lima y antiguo Caballero de la Orden de Alcántara de España, dos chacras "que están juntas e incorporadas y linda con chacra que fue de Gonzalo Camarena y del Convento de Nuestra Señora de las Mercedes, con sus Casas Ranchos, Olivares, huertas, corrales y lo demás [...]”, por el precio de 33 mil pesos de a ocho reales (ibídem, op. cit., p. 287). Pero cuando el nuevo propietario Arano empezó a conocer los problemas judiciales y económicos complejos que complicaban a las tierras adquiridas, dona su heredad al Noviciado Vocacional de la Compañía de Jesús, también llamada Casa de Probación de San Antonio Abad, de Lima, año de 1655. Pero al parecer los problemas no terminaban en tales tierras, porque desde 1661 á 1697 se cuentan cinco sucesivos adquirientes, siendo el último don Antonio de Llano (representante de los jesuitas). Así, el 9 de octubre de 1697, los jesuitas del Noviciado de San Antonio Abad de Lima nombraron a su adquirida hacienda con el nombre de San Francisco de Borja, cuyos riegos procederían del canal rimense Huatica y no del "río Surco" tradicional, lo cual sin embargo siempre era condicional, pues podría acceder a ambas fuentes de agua (ibidem, p.295). Sin embargo, las vicisitudes productivas, financieras y administrativas de la hacienda San Borja continuaron en las décadas finales del Siglo XVII y la Compañía de Jesús fracasó en la tenencia agropecuaria de la propiedad en el siglo XVIII, reiniciándose las ofertas de venta, sucediéndose administraciones tras administraciones particulares a lo largo de los siglos venideros hasta el advenimiento del distrito San Borja contemporáneo (segunda mitad del siglo XX).

\section{BibliografíA}

AGUILAR, Pedro G.

1985 “Fauna de las lomas costeras del Perú". En: Rev. Boletín de Lima, año VII, Editorial Los Pinos. Lima.

ALBORNOZ, Cristóbal de

1967 “Un Inédit de Cristóbal de Albornoz: La Instrucción para descubrir todas las Guacas del Pirú y sus Camayos y Haziendas par Pierre Duviols". Journal de la Societé des Americanistés, Musee de L'Homme, Tome LVI-1, pp. 7-39. 
1989 “Instrucción para descubrir todas las Guacas del Perú y sus Camayos y Haziendas”. En: Henrique Urbano y Pierre Duviols, edits., Fábulas y ritos de los incas. Madrid, Historia 16.

ALTAMIRANO, E., Alfredo

1983 "La fauna de Huachipa, Valle del Rímac" - Informe Arqueológico. En: Boletín del Museo Nacional de Arqueología y Antropología, Nº, Lima.

BROMLEY, Juan

1935-1963 Libro de Cabildos de Lima. Imprenta Torres Aguirre. Tomos IX al XXIII. Lima.

BUENO MENDOZA, Alberto

1970 Cajamarquilla y Puruchuco. Servicios de Publicaciones. Museo de Arqueología y Etnología de la UNMSM - Lima.

1974-1975 “Cajamarquilla y Pachacamac: Dos ciudades de la Costa Central del Perú. XXXIX Congreso Internacional de Americanistas, Lima, 1970". Boletín Bibliográfico de Antropología Americana, Vol. XXXVII (46), pp. 171-201, México.

1975 “La Zona Arqueología de Cajamarquilla, Valle del Rímac”. Revista Proceso, (4), pp. 17-21. Órgano Cultural de la Universidad Nacional del Centro. Huancayo.

1977a “Perú: Materiales para el estudio de la Arquitectura Arqueológica”. Serie Estudios Técnicos I. Editorial Universo. Lima, $124 \mathrm{pp}$.

1977b “Guaycán de Cieneguilla”. En: Revista Espacio (1), Edit. Valcárcel, Lima.

1977c “El Señorío de Ichimay”. En: Revista Espacio (2), Edit. Valcárcel, Lima.

1979 “Urbanismo Prehispánico Tardío en Lurín”. En: Rev. Inca, Segunda Época III (6), pp. 59-69. Revista del Centro de Estudiantes de Arqueología, UNMSM, Lima.

1982a “El Antiguo Valle de Pachacamac: Espacio, Tiempo y Cultura". En: Rev. Boletín de Lima V (24), pp. 5-27. Editorial Los Pinos, Lima (El artículo se publicó en tres números; 24, 25 y 26).

1982b “El Antiguo Valle de Pachacamac: Espacio, Tiempo y Cultura". Separata del Boletín de Lima, números 24, 25 y 26, pp. 3-52, Edit. Los Pinos. Lima.

1983 “Arquitectura Pre-Chavín en los Andes Centrales”. En: Rev. Boletín de Lima, V (28), pp. 11-28. Lima, Edit. Los Pinos.

1984 “Cieneguilla: Arqueología, Historia y Turismo”. En: Rev. Espacio, Edit. Valcárcel, № 20, Lima.

1988 "Hallazgo de Quipu en Pachacamac y Cieneguilla". En: Rev. Espacio, Edit. Valcárcel, N²8, Lima.

1989 “Arqueología de Ancón reclama un futuro diferente”. En: Rev. Espacio, N 27, Edit. Valcárcel, Lima.

BUENO MENDOZA, Alberto y ANSELMO LOZANO Calderón

1990 “La Marka de Lima: Arqueología y Etnohistoria”. En: Rev. Humanitas 15. Boletín del Departamento Académico de Ciencias Humanas, Universidad de Lima. Julio-septiembre. Lima, pp. $15-23$. 
COOK, David Noble

1965 La Población Indígena en el Perú Colonial. Imp. de la Universidad Nacional del Litoral (Santa Fe), Argentina.

1981a Demografic Collapse Indian Peru, 1520-1560. Cambridge University Press. Cambridge.

1981b La Catástrofe demográfica andina. Perú 1520-1620. Fondo Editorial, Pontificia Universidad Católica del Perú, Lima, 416 pp.

CÁRDENAS AYAIPOMA, Mario

1989 La Población Aborigen del Valle de Lima en el Siglo XVI. CONCYTEC Edits., Lima.

DE LEÓN PORTOCARRERO, Pedro

2009 Descripción del Virreinato del Perú. Universidad Particular Ricardo Palma, Lima, 232 pp.

DEL BUSTO DUTHURBURU, José Antonio

2006 Historia Cronológica del Perú. Petroperú S.A. Edits. (Edics. Copé), Lima, 749 pp.

DESCARTES, Renato.

1910 “La Geometría”. En: Oeuvres de Descartes. Publiées par V. Cousin, t. 5, Paris.

1971 “Reglas para la dirección del espíritu”. En: Obras de Renato Descartes. Edit. de Ciencias Sociales, Instituto Cubano del Libro, La Habana, Cuba.

FLOREZ-ZÚÑIGA, Fernando.

2008 Haciendas y Pueblos de Lima-Historia del Valle del Rímac. Fondo Editorial del Congreso del Perú y Municipalidad Metropolitana de Lima, Tomos I (505 pp.) II (727 pp.), Lima, + mapas.

MIDDENDORF, Ernst W.

1973 Perú. Pubs. de la Universidad Nacional Mayor de San Marcos, Tomo II, Lima, 306 pp.

ROSTWOROWSKI, María.

1978 Señoríos Indígenas de Lima y Canta. Instituto de Estudios Peruanos, Lima.

1981-1982 “Dos probanzas de don Gonzalo, Curaca de Lima (1555-1559)”. Rev. Histórica, Publicación de la Academia Nacional de Historia, T. XXXIII, Lima, pp. 103-173.

TELLO, Julio César

1999 “Arqueología del Valle de Lima”. Cuadernos de Investigación del Archivo Tello, № 1. Museo de Arqueología y Antropología, Universidad Nacional Mayor de San Marcos, Lima, 137 pp.

VILLAR CÓRDOVA, Pedro

1935 Arqueología del Departamento de Lima (Homenaje al IV Centenario de la Fundación de Lima: o Antigua "Ciudad de los Reyes"), Lima, 423 pp.

1942 “Las Ruinas de Ascona". En: Rev. Histórica, Publicación de la Academia Nacional de Historia, T. XV (II), Lima, pp. 248-255. 
VILLIGER, Fernando y Rogger RAVINES

2009 “Lima. Homenaje a la Ciudad de Lima”. En: Boletín de Lima, Vol. XXVII, №139-142, año 27, Lima, pp. 518 pp.

SHADY SOLÍS, Ruth

1982 “La Cultura Nievería y la interacción social en el mundo andino en época Huari”. En: Rev. Arqueológicas, Museo Nacional de Arqueología y Antropología, №19, Lima, pp. 7-108.

SQUIER, Ephraim George

1974 Un viaje por tierras incaicas. Crónica de una expedición arqueológica (1863-1865). Edit. Los Amigos del Libro, La Paz-Cochabamba.

ZAVALA, Silvio

1978-1980 El servicio personal de los indios del Perú. El Colegio de México, Tomos I, II y III, México. 